\title{
The Lightning Distribution of Tropical Cyclones over the Western North Pacific
}

\author{
SHU-JENG LiN ${ }^{\mathrm{a}}$ AND KUN-HSUAN CHOU ${ }^{\mathrm{b}}$ \\ ${ }^{a}$ Research Center for Environmental Changes, Academia Sinica, Taipei, Taiwan \\ ${ }^{\mathrm{b}}$ Department of Atmospheric Sciences, Chinese Culture University, Taipei, Taiwan
}

(Manuscript received 4 October 2019, in final form 23 August 2020)

\begin{abstract}
This study examines the characteristics of tropical cyclone (TC) lightning distribution and its relationship with TC intensity and environmental vertical wind shear (VWS) over the western North Pacific. It uses data from the World Wide Lightning Location Network and operational global analysis data from National Centers for Environmental Prediction Final Analysis for 230 TCs during 2005-17. The spatial distribution of TC lightning frequency and normalized lightning rate demonstrates that the VWS dominates the azimuthal distribution of the lightning. The flashes are active in the downshear-left side of the inner core and the downshear-right side of the outer region. TC lightning distribution for various VWS strengths and TC intensities are further investigated. As VWS increases, the flashes of lightning become more asymmetric and exhibit a higher proportion at the outer region of the downshear side. Moreover, the same features occur as TC intensity decreases. A series of composite analyses indicated that stronger TCs with weaker VWS exhibit a more compact and symmetric lightning distribution, whereas weaker TCs with stronger VWS have a more asymmetric lightning distribution. Furthermore, the TC lightning distribution and its association with TC intensity changes are also examined for three lead times. Results show that among the composite analyses of five TC intensity changes, the lightning distribution for rapid intensification type exhibits more inner-core lightning and is more axisymmetric than the distributions for other categories. These features result from favorable environmental conditions comprising greater upper-level divergence, sea surface temperature, maximum potential intensity, and weaker vertical wind shear.
\end{abstract}

\section{Introduction}

A key challenge for tropical cyclone (TC; see Table 1 for this and other acronyms used in this paper) research is to achieve accurate TC track and intensity forecasts to provide adequate warning for areas that TCs are entering as well as to anticipate the severity of damage. In the past decade, errors in TC track forecasting have declined considerably, but the accuracy of TC intensity forecasts could be much improved (Marks et al. 1998; DeMaria et al. 2014; Kaplan et al. 2015; Cangialosi and Franklin 2014; Dong and Zhang 2016). Particularly since the beginning of the twenty-first century, intense TCs have gradually increased in frequency, with maximum wind speeds reaching unprecedented levels (Lander et al. 2014; Lin et al. 2014; Huang et al. 2017). The formation of these intense TCs is usually accompanied by the process of rapid intensification (RI; Kaplan and DeMaria 2003; Kaplan et al. 2010). Such problems have also continued to hinder researchers and forecasters seeking to determine how key information regarding changes in TC intensity may be accurately assessed through limited observations.

Some factors, including environmental conditions such as sea surface temperature, ocean heat content, vertical wind shear (VWS), upper-level divergence, and midlevel relative humidity, can influence intensity changes in TCs. Lightning densities in the inner core (within $100 \mathrm{~km}$ ) and outer band $(200-300 \mathrm{~km})$ of TCs have been added as reference indicators for RI forecasting. Lightning data have also begun to be widely used in TC research. In particular, after the development of the World Wide Lightning Location Network (WWLLN), a series of

Corresponding author: Kun-Hsuan Chou, zkx@faculty.pccu.edu.tw articles emerged that discussed the association between TC intensity and structure and lightning frequency (LF). In principle, the distribution and locations of areas of high lightning density in TCs are generally consistent with strong convective regions, which are usually located near the inner-core eyewall and outer rainbands (Abarca et al. 2011; DeMaria et al. 2012; Zhang et al. 2012; Stevenson et al. 2016; Xu et al. 2017; Fierro et al. 2018). Lightning distribution and location are also affected by VWS. Lightning occurs primarily on the downshear side, and the lightning in the inner core is often found in the downshear-left quadrant, whereas the lightning in outer bands is observed in the downshear-right quadrant (Corbosiero and Molinari 2002, 2003; Abarca et al. 2011; Fierro and Mansell 2017; Stevenson et al. 2014, 2016, 2018; Wang et al. 2018; Zhang et al. 2019). Although the TC motion has also been proposed to be relevant to distribution and locations of lightning (Corbosiero and Molinari 2002, 2003; Abarca et al. 2011; Stevenson et al. 2016; Fierro et al. 2018; Wang et al. 2018), compared with the effect of VWS, the effect of TC motion is less important. Evidence has also indicated fluctuations in lightning activity are attributable to the diurnal cycle; more lightning activity is generally observed at night than during the day because of the typical overnight peak in oceanic convection and the greater detection efficiencies of the WWLLN and the Geostationary Lightning Mapper at night (Stevenson et al. 2016; Fierro et al. 2018; Ditchek et al. 2019).

Most studies have indicated that more lightning activity is usually accompanied by a higher probability of the TC intensity increasing. However, some discrepancies have occurred in the conclusions of more detailed analyses. For example, some have contended that high-density inner-core lightning bursts are strong predictors of intensity increase or RI (Thomas et al. 2010; Abarca et al. 2011; Bovalo et al. 2014; Zhang et al. 2015; 
TABLE 1. List of acronyms used in this paper.

\begin{tabular}{|c|c|}
\hline Acronym & Definition \\
\hline $\mathrm{AF}$ & Adjustment factor \\
\hline D200 & $200 \mathrm{hPa}$ divergence (SHIPS predictor) \\
\hline ENP & Eastern North Pacific \\
\hline FLASH & Lightning flash \\
\hline IN & Intensification, +5 to $+15 \mathrm{kt}(6 \mathrm{~h})^{-1}$ \\
\hline ITP & Individual time period \\
\hline JTWC & Joint Typhoon Warning Center \\
\hline $\mathrm{LD}$ & Lightning density \\
\hline LD-1R & Lightning density calculated within the range of the RMW \\
\hline LD-5R & Lightning density calculated within 5 times the RMW \\
\hline LF & Lightning frequency \\
\hline LStd & Standard deviation value of lightning frequency \\
\hline MPI & Maximum potential intensity from K. Emanuel equation (SHIPS predictor) \\
\hline MTC & Moderate tropical cyclone, maximum sustained wind 64-96 kt \\
\hline MVS & Moderate vertical wind shear strength, shear magnitude $10-17 \mathrm{kt}$ \\
\hline NA & North Atlantic \\
\hline NCEP & National Centers for Environmental Prediction \\
\hline NStd & Standard deviation value of normalized lightning frequency \\
\hline $\mathrm{OHC}$ & $\begin{array}{l}\text { Climatological ocean heat content from } 2005 \text { to } 2010 \text { Navy Coupled Ocean Data Assimilation analyses } \\
\text { (SHIPS predictor) }\end{array}$ \\
\hline RHLO & $850-700 \mathrm{hPa}$ relative humidity (SHIPS predictor) \\
\hline RI & Rapid intensification, intensity change $\geq+15 \mathrm{kt}(6 \mathrm{~h})^{-1}$ \\
\hline RMW & Radius of maximum wind \\
\hline RW & Rapid weakening, intensity change $\leq-15 \mathrm{kt}(6 \mathrm{~h})^{-1}$ \\
\hline SHIPS & Statistical Hurricane Intensity Prediction Scheme \\
\hline SHRD & 850-200 hPa shear magnitude (SHIPS predictor) \\
\hline SST & Reynolds sea surface temperature (SHIPS predictor) \\
\hline ST & Steady state, intensity change -5 to $+5 \mathrm{kt}(6 \mathrm{~h})^{-1}$ \\
\hline STC & Strong tropical cyclone, maximum sustained wind $\geq 96 \mathrm{kt}$ \\
\hline SVS & Strong vertical wind shear strength, shear magnitude $>17 \mathrm{kt}$ \\
\hline TC & Tropical cyclone \\
\hline TRMM LIS/OTD & Tropical Rainfall Measuring Mission Lightning Image Sensor/Optical Transient Detector \\
\hline Vmax & Maximum sustained wind \\
\hline VWS & Vertical wind shear \\
\hline WE & Weakening, intensity change -15 to $-5 \mathrm{kt}(6 \mathrm{~h})^{-1}$ \\
\hline WNP & Western North Pacific \\
\hline WTC & Weak tropical cyclone, maximum sustained wind 34-64 kt \\
\hline WVS & Weak vertical wind shear strength, shear magnitude $0.1-10 \mathrm{kt}$ \\
\hline WWLLN & World Wide Lightning Location Network \\
\hline
\end{tabular}

Stevenson et al. 2018). Others have suggested that inner-core lightning bursts, in reality, represent the end of intensification, whereas lightning bursts in the outer band are the main indicator of intensity increase (DeMaria et al. 2012; Stevenson et al. 2016; Xu et al. 2017; Fierro et al. 2018; Fierro and Mansell 2018). Another area of contention concerns whether greater lightning density follows higher TC intensity (Pan et al. 2014; Fierro et al. 2018). Some studies have indicated that high-density lightning is more likely to occur in weak TCs (Abarca et al. 2011; DeMaria et al. 2012; Zhang et al. 2015; Stevenson et al. 2018; Wang et al. 2018). However, this point of disagreement may be attributable to the highly random occurrence of lightning, which varies between TCs (Fierro et al. 2018; Stevenson et al. 2018). Differences in sampling or in the environmental conditions of TCs in different areas may cause the observation of markedly different lightning characteristics. Therefore, when lightning data are used to predict TC intensity changes, storm status and characteristics of the surrounding environment should be considered. For example, Stevenson et al. (2018) found distinct differences, mainly in the seasonal distribution and in the relationship between lightning activity and TC intensity changes, in the lightning characteristics of eastern North Pacific (ENP) and North Atlantic (NA) TCs.

The aforementioned contentions were based mostly on analyses of NA and ENP TC lightning. Studies of the western North Pacific (WNP) have not identified noticeable differences in lightning compared with the NA and ENP. For example, Pan et al. (2014) reported that maximum lightning activity occurs prior to peak TC intensity. Zhang et al. (2015) used the WWLLN dataset to study lightning activity and the relationship between inner-core lightning and TC intensity changes over the WNP from 2005 to 2009. Lightning was concluded to be more likely to occur in weak storms at tropical depression and tropical storm intensity levels. The highest lightning density in the inner core appeared in storms that would proceed to undergo rapid intensity changes during the 
following $24 \mathrm{~h}$. It was claimed that the inner-core lightning activity may be a suitable indicator for predicting RI in Northwest Pacific storms. Wang et al. (2018) applied WWLLN data to investigate the characteristics of lightning activity and its relationship with environmental dynamic and thermodynamic parameters for WNP storms from 2005 to 2016. They found that the highest lightning density in the inner core occurs when a TC is at the tropical depression stage, and the secondary maximum occurs at the super typhoon intensity stage. In the outer rainbands, lightning density changed slightly with TC intensity. Moreover, asymmetric lightning distribution with respect to VWS was observed. Zhang et al. (2018) also used the WWLLN dataset to investigate lightning outbreaks and convective evolution in the inner core of Super Typhoon Haiyan (2013). Three major inner-core lightning outbreaks and convective bursts were observed during the RI, maximum intensity, and weakening stages. They also claimed that the radial and azimuthal distributions of lightning outbreaks within the inner core provided information indicative of the relationships between convective structure and intensity changes of Haiyan.

However, some characteristics were specific to the WNP, such as greater climatic values for lightning over the South China Sea than over other open waters, greater lightning activity in an El Niño year than in a La Niña year, and more frequent lightning flashes when TCs pass over land (Zhang et al. 2012, 2018; Pan et al. 2014). Furthermore, the generation and development of TCs in the NA are greatly affected by easterly waves and VWS, but TCs in the WNP are more likely affected by the summer monsoon and ocean heat flux. Evidently, the environmental characteristics of the WNP, which sees the greatest density of TC activity globally and normally exhibits northeasterly VWS, decidedly differ from those of the NA and ENP. Although a few studies have explored lightning and TCs in the WNP, lightning activity and its relationship with TC intensity change remain poorly researched; and little research interest has been devoted to the symmetry of innercore lightning distribution, and analyses of radius of maximum wind (RMW)-relative frameworks are lacking. This study thus applied RMW-relative perspective, which is commonly used in the NA and ENP to TC lightning in the WNP and further evaluated the influences of large-scale environments on the TC innercore lightning distribution. Using WWLLN global lightning data, a 13-yr survey of TC lightning characteristics was conducted to examine the spatial distribution of lightning activity and its relationship with intensity changes in WNP TCs.

The remainder of this paper is organized as follows: section 2 describes the data sources and research methods used in the study. Section 3 discusses the overall distribution of TC lightning with respect to VWS, motion, and intensity. Section 4 explores characteristics of the spatial distribution of TC lightning and its relationship with intensity change for five categories of intensity change across three lead times. Furthermore, the environmental conditions that contribute to the inner-core lightning features are also addressed. Finally, section 5 presents discussions and conclusions.

\section{Data and methods}

\section{a. Lightning data}

The lightning data used in this study are from the WWLLN, founded by the University of Washington; since 2005, it has placed more than 70 sensors around the globe. These sensors can detect very low-frequency radio waves (Abarca et al. 2011). The detection principle of these sensors is as follows: when energy generated by lightning passes through the ionosphere, these signals are reflected onto Earth's surface and transmitted to the sensors. This system can detect lightning from thousands of kilometers away, most of which is cloud-to-ground lightning. This lightning data collection has approximately $10 \mathrm{~km}$ location accuracy (Rodger et al. 2009). Due to the high station density and low attenuation of very low-frequency electromagnetic waves over the ocean, the WWLLN exhibits high detection efficiency over the oceanic area (Hutchins et al. 2012). In the early stages (before 2008) of this system, however, its detection efficiency was lower because it had only implemented a relatively small number of sensors. Several studies have used the climatic values of lightning frequency provided by the Tropical Rainfall Measuring Mission (TRMM) Lightning Image Sensor (LIS)/Optical Transient Detector (OTD) to evaluate the yearly lightning detection efficiency of the WWLLN and calculate the ratio of two sets of lightning data from a specific region to serve as the adjustment factor (AF) for determining yearly WWLLN detection efficiency (DeMaria et al. 2012; Pan et al. 2014; Zhang et al. 2015).

To reduce differences in detection efficiency attributable to the number of sensors, TC-sensitive areas between $125^{\circ} \mathrm{E}$ and $180^{\circ}$ and between $0^{\circ}$ and $45^{\circ} \mathrm{N}$, excluding landforms, were selected (see red frame in Fig. 1a). Lightning data for annual mean climatology from the TRMM LIS/OTD were compared with yearly mean LFs from the WWLLN to calculate the AF corresponding to each year in the 2005-17 period (Table 2). The AF decreased substantially between 2008 and 2009 due to the addition of dozens of sensors to the WWLLN in 2008. The highest and lowest AFs occurred in 2007 and 2017, respectively, and these are the cases presented in Figs. 1c-f. After AFs were taken into account, the TC LFs between 2007 and 2017 exhibited almost no difference (Figs. 1e,f). The detection efficiency is also an area requiring particular attention when WWLLN data are used to evaluate interannual lightning characteristics.

\section{b. TC information}

Data such as TC time, location, RMW, maximum sustained wind (Vmax), and lowest central pressure were taken from best track data issued by the Joint Typhoon Warning Center (JTWC) every $6 \mathrm{~h}$. Linear interpolation was employed to interpolate TC data as hourly data. To satisfy the TC case selection criteria for this study, the Vmax of a TC had to reach $34 \mathrm{kt}(1 \mathrm{kt} \approx$ $0.51 \mathrm{~m} \mathrm{~s}^{-1}$ ) or more and maintain that intensity for at least $24 \mathrm{~h}$. Using this screening method, a total of $230 \mathrm{TC}$ cases from 2005 to 2017 were selected, with an average of approximately 17.7 cases per year. TC cases were categorized as weak (WTC, 34-64 kt), moderate (MTC, 64-96 kt), or strong (STC, $\geq 96 \mathrm{kt}$ ) according to the JTWC's Vmax in order to evaluate differences in the lightning characteristics of TCs with varying intensities.

\section{c. Data analysis methods}

Time, longitude, and latitude data from the WWLLN and JTWC best track were used to find lightning located within $500 \mathrm{~km}$ of hourly TC centers and to calculate LF within a 
(a)

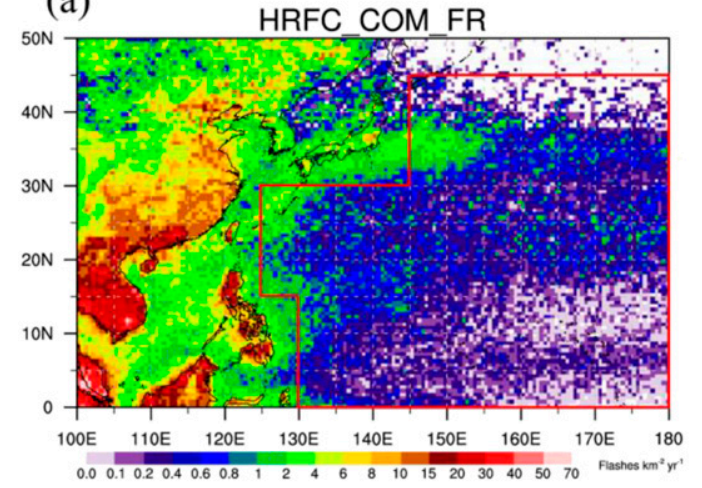

(c)

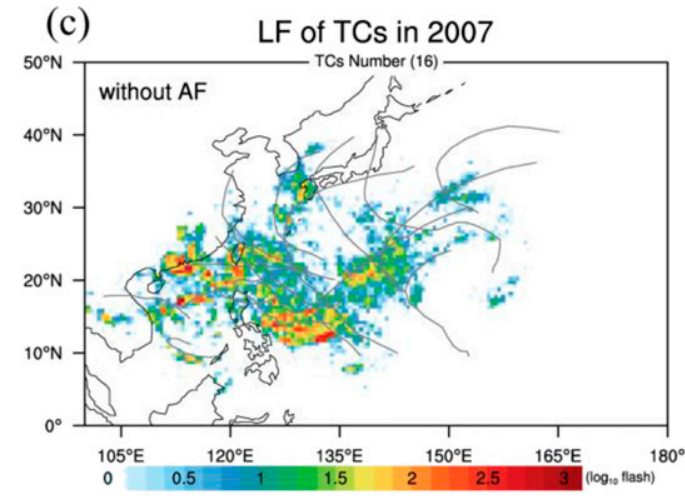

(e) Adjusted LF of TCs in 2007

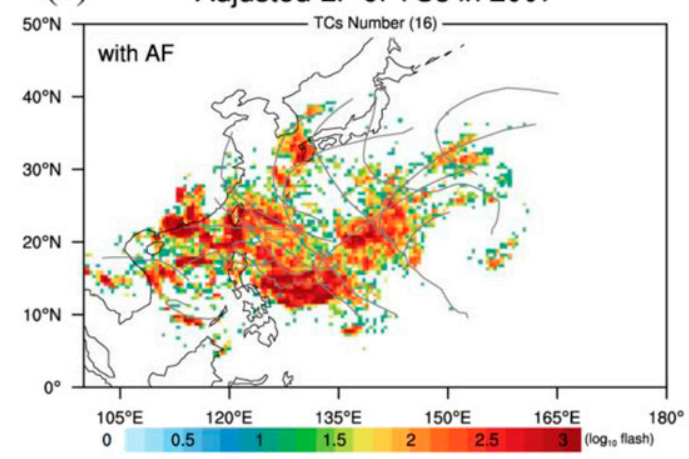

(b)

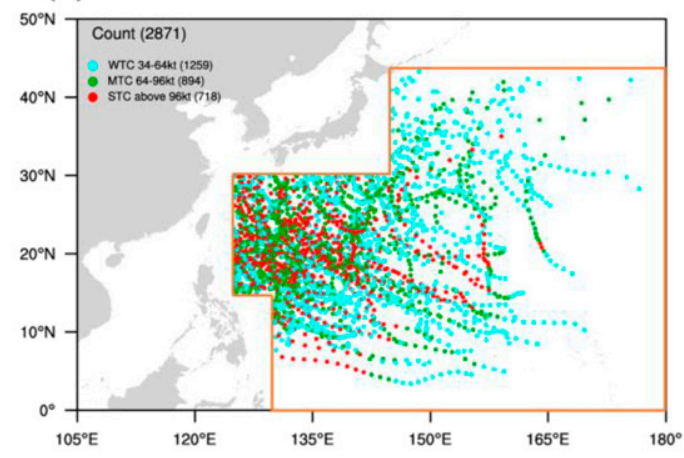

(d) LF of TCs in 2017

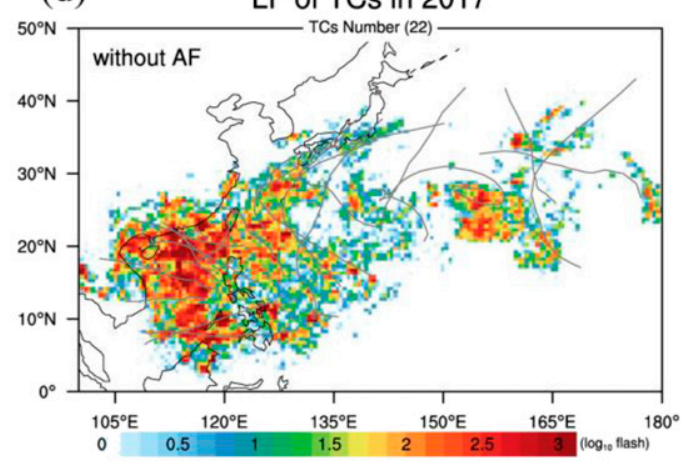

(f) Adjusted LF of TCs in 2017

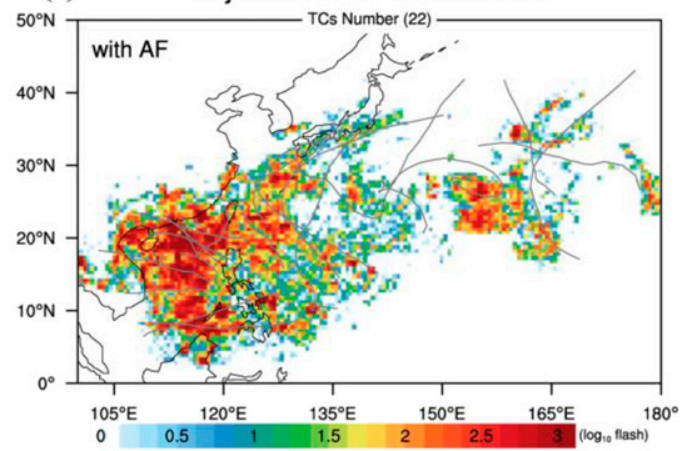

FIG. 1. (a) Lightning density for annual mean climatology data from the TRMM OTD/LIS (1982-2014) over the WNP. (b) The selected TCs plotted in three intensity categories from the JTWC 6-hourly best track dataset during 2005-17. The lightning density yearly mean within $5^{\circ}$ of latitude for each TC over the WNP in (c) 2007 and (d) 2017 according to WWLLN data. (e),(f) As in (c) and (d), but that the adjustment factor is taken into account. The red boxes in (a) represent the areas in which the adjustment factors are calculated using the ratio of WWLLN lightning density to OTD/LIS lightning density. The black lines in (c)-(f) represent the TC tracks. The lightning density units for (a) are flashes $\mathrm{km}^{-2} \mathrm{~h}^{-1}$ and for (c)-(f) are $\log _{10}$ flashes per $0.5^{\circ}$ latitude $\times 0.5^{\circ}$ longitude.

$0.5^{\circ} \times 0.5^{\circ}$ grid (e.g., Figs. $\left.1 \mathrm{c}, \mathrm{d}\right)$. Graphs of the annual frequency distribution of lightning in 2007 (Fig. 1c) and 2017 (Fig. 1d) were employed; LF in 2017 was considerably greater than in 2007. In addition to differences in the number of cases analyzed between the two years, this finding was also related to the aforementioned smaller detection efficiency of established WWLLN sensors prior to 2008 .

One of the foci of this study was the analysis of the spatial distribution of lightning activity for TC coordinates relative to the RMW. Operational centers estimate TC intensity and structure parameters using the Dvorak method (Velden et al. 2006), which is based on relationships between TC intensities and the structures of cloud fields on satellite images in the visible and infrared ranges. The RMW is defined as the distance between the warmer TC center and the colder eyewall rings, determined according to the infrared imagery of cloudtop temperature fields (Permyakov et al. 2019). Because no routine reconnaissance aircraft missions for TCs have flown 
TABLE 2. Yearly adjustment factors for the WNP ocean area are determined in this study. Adjustment factors are calculated by the ratio of yearly mean lightning density from the WWLLN to the annual mean lightning density climatology data (1998-2014) from the TRMM LIS/OTD in the three rectangular areas seen in Fig. 1: $0^{\circ}-15^{\circ} \mathrm{N}, \quad 130^{\circ} \mathrm{E}-180^{\circ} ; \quad 15^{\circ}-30^{\circ} \mathrm{N}, \quad 125^{\circ} \mathrm{E}-180^{\circ} ;$ and $30^{\circ}-45^{\circ} \mathrm{N}$, $145^{\circ} \mathrm{E}-180^{\circ}$.

\begin{tabular}{cc}
\hline \hline Year & Adjustment factor \\
\hline 2005 & 10.112 \\
2006 & 10.067 \\
2007 & 12.406 \\
2008 & 7.339 \\
2009 & 2.898 \\
2010 & 2.742 \\
2011 & 2.760 \\
2012 & 2.071 \\
2013 & 2.012 \\
2014 & 1.741 \\
2015 & 2.562 \\
2016 & 2.338 \\
2017 & 1.526 \\
\hline
\end{tabular}

over the WNP since 1987, no routine or in situ observations for RMW have been conducted in the past three decades; thus, relevant studies on RMW estimates or errors are unavailable.

Nevertheless, to address the reliability of JTWC RMW data, the distribution of RMW values for all TCs in three intensity categories were examined (Fig. 2). For all the WNP TCs during the 2005-17 period (Fig. 2a), the characteristics of RMW values were closely linked with TC intensity. The stronger TCs exhibited smaller RMW values, whereas the weaker TCs exhibited larger RMW values. The results for all the analyzed TCs in this study (Fig. 2b) are highly consistent with the combined results for all of the samples. The mean RMW values in WTCs, MTCs, and STCs were approximately 60,40 , and $30 \mathrm{~km}$, respectively. This overall RMW value evaluation demonstrates that the JTWC-estimated RMW values are reasonable, although their accuracy over the WNP remains unknown. Kossin et al. (2007) examined the RMW estimated errors by comparing values from aircraft reconnaissance over the NA. They found the mean absolute error of the estimated RMW to be $10.2 \mathrm{~km}$.

In this study, the RMW data estimated by the JTWC best track dataset were utilized, and lightning data within 5 times the RMW for all TC cases were selected for analysis. Two metrics were defined to quantify the lightning distribution around TCs. LF was a simple calculation of the cumulative number of lightning flashes within a grid point, and normalized LF was calculated using twice-normalized frequency. In the first normalization, the LFs at grid points for individual time periods (ITPs, hourly) were normalized separately using Eq. (1). In the second normalization, the normalization results for all time periods were totaled. The cumulative result was then normalized using Eq. (2):

$$
\operatorname{AveLF}(i)=\frac{\int_{j=1}^{j=n} \frac{\operatorname{LF}_{(i, j)}}{\operatorname{MaxLF}_{(j)}}}{n},
$$
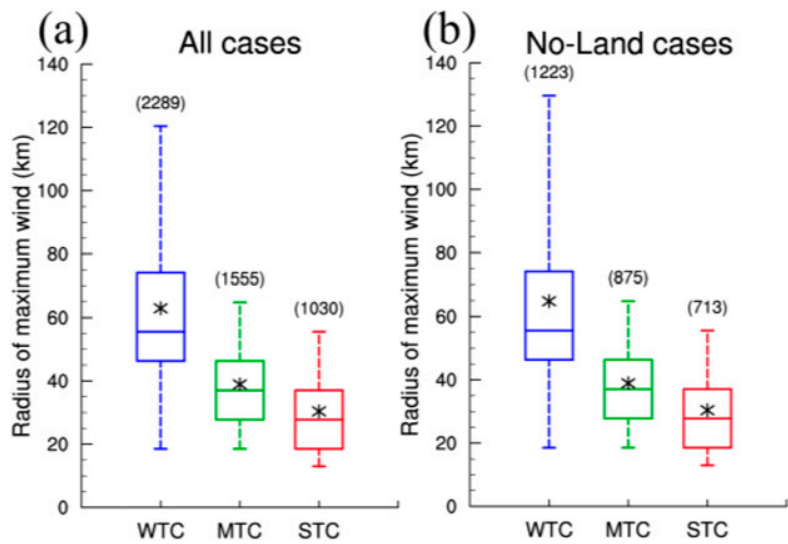

FIG. 2. Boxplots of the RMW for three TC intensity types for (a) all and (b) no-land effect cases over the WNP from the JTWC best track dataset during 2005-17. The data range between 2.5 th and 97.5 th percentiles of each category are calculated. Blue, green, and red box plots represent weak, moderate, and strong TC intensity, respectively. The asterisk denotes the mean value, and the number in parentheses represents the sample size.

where AveLF is the average normalized LF in the first normalization, MaxLF is the maximum LF for grids within 5 times the RMW, $i$ is the grid within 5 times the RMW, $j$ is the ITP for an analyzed case, and $n$ is the number of the ITPs:

$$
\operatorname{NorLF}(i)=\frac{\operatorname{AveLF}_{(i)}}{\operatorname{MaxAveLF}}
$$

where NorLF is the normalized LF after the second normalization, and MaxAveLF is the maximum AveLF for grids within 5 times the RMW.

The LF primarily exhibited the spatial distribution of original lightning frequencies; the normalized LF filtered dominant phenomena caused by cases of extreme lightning bursts and was not affected by AF.

The azimuth angles for the aforementioned spatial representations of lightning activity were also converted to correspond with the TC motion and the VWS direction, which are often connected with convective asymmetry. TC motion was calculated using the longitude and latitude after interpolation of hourly TC centers from the JTWC best track. For VWS, wind field data from the analysis field of the National Centers for Environmental Prediction (NCEP) Final Analysis (FNL) were used to calculate wind vector differences between 200 and $850 \mathrm{hPa}$ and were averaged within an annulus extending $2^{\circ}-8^{\circ}$ from the storm's center (Chou et al. 2019). To evaluate the degree of confidence of calculation results of VWS from NCEP-FNL, the VWS data were further compared with those from the Statistical Hurricane Intensity Prediction Scheme (SHIPS) where wind data over the $200-800 \mathrm{~km}$ annulus were calculated. The comparison results for zonal and meridional wind components exhibited high goodness of fit between the SHIPS data and VWS data calculated from NCEP-FNL (figure not shown). On the basis of NCEP-FNL calculations, shear strength was categorized as weak (WVS, 0.1$10 \mathrm{kt}$ ), moderate (MVS, 10-17kt), or strong (SVS, > 17kt); 
these categorizations were used to examine lightning characteristics at environmental VWS of varying strengths.

Because another focus of this study was the association between TC intensity changes and lightning distribution, the relationship between the time of lightning occurrence and intensity changes had to be defined. The period within $6 \mathrm{~h}$ before lightning occurrences constituted the lead time of $0 \mathrm{~h}$, the period 6 to $12 \mathrm{~h}$ prior to lightning occurrences constituted the lead time of $-6 \mathrm{~h}$, and the period $6 \mathrm{~h}$ after lightning occurrences constituted the lead time of $+6 \mathrm{~h}$. Furthermore, TC Vmax data from JTWC were used to calculate changes in wind speed every $6 \mathrm{~h}$ according to the aforementioned three lead times. Intensity change was divided into the following five categories: rapid weakening $\left[\mathrm{RW}, \leq-15 \mathrm{kt}(6 \mathrm{~h})^{-1}\right]$, weakening [WE, $-15 \mathrm{kt}(6 \mathrm{~h})^{-1}$ to $-5 \mathrm{kt}(6 \mathrm{~h})^{-1}$ ], steady state $\left[\mathrm{ST},-5 \mathrm{kt}(6 \mathrm{~h})^{-1}\right.$ to $\left.+5 \mathrm{kt}(6 \mathrm{~h})^{-1}\right]$, intensification [IN, $+5 \mathrm{kt}$ $(6 \mathrm{~h})^{-1}$ to $\left.+15 \mathrm{kt}(6 \mathrm{~h})^{-1}\right]$, and RI $\left[\geq+15 \mathrm{kt}(6 \mathrm{~h})^{-1}\right]$. Such categorization was then used to examine the characteristics of lightning activity and spatial distribution at various lead times and intensity changes. To eliminate the influence of orographic effects, the lightning data analyzed in this study excluded TC cases that occurred during periods when TCs were approaching areas in the Philippines, Taiwan, and Japan (Fig. 1b). In this study, six large-scale predictors from the SHIPS diagnostic data were selected to investigate why inner-core lightning may be occurring and what mechanisms could contribute to the lightning distributions that result in TC intensity changes. These predictors were the $850-200 \mathrm{hPa}$ vertical shear magnitude (SHRD), $200 \mathrm{hPa}$ divergence (D200), 850-700 hPa relative humidity (RHLO), maximum potential intensity (MPI), sea surface temperature (SST), and climatological ocean heat content (OHC), which are commonly used as predictors for RIindex development to estimate RI probability (Kaplan et al. 2015). Based on the comparisons of intensity change and these predictors for the studied samples, it is found that except for the D200, these predictors all exist a systematic difference for different intensity change types of TCs. When TCs strengthen faster, they are usually embedded in the environments with greater MPI, RHLO, SST, and OHC values, while weaker VWS values; and vice versa (figure not shown).

\section{Overall distribution of TC lightning}

\section{a. Lightning distribution according to VWS direction, TC intensity, and TC motion}

In this study, 230 TC cases from 2005 to 2017 were analyzed. To evaluate the relationship between lightning activity and fluctuations of TCs, only samples without orographic effects were included in the following composite analyses (samples within the orange frame in Fig. 1b). As shown in Fig. 3, composite analyses of LF (Figs. 3a,b), adjusted LF (Figs. 3c,d) and normalized LF (Figs. 3e,f) were conducted within 5 times the RMW for 230 TC cases, using all analyzed ITPs. Notably, the different numbers of ITPs between the composite analyses of the vertical shear direction $($ ITP $=7869)$ and of storm motion $($ ITP $=7857)$ stemmed from the different zero-value samples of environmental shear and storm translation speed. Maximum frequency occurred within the inner edge of the downshear-left
RMW (Fig. 3a); the upshear right within the RMW exhibited relatively low LF. A relatively large LF distribution is evident as the radius travels outward, gradually shifting to the downshear right (3-5 RMW), and a relatively less LF in the outer areas also shifts position to the upshear left. The same method was applied to the composite analysis undertaken with respect to the TC motion (Fig. 3b); the maximum LF is evident at the left side of the motion within the RMW, whereas in the outer areas, LF is slightly greater at the front left of the motion. Overall, motion-relative azimuthal asymmetries in the lightning distribution are less discernible than shearrelative asymmetries.

To assess the possible effects of differences in the detection efficiency of the WWLLN, a composite analysis was also conducted on yearly LF data after taking into account AF (Figs. 3c,d). Compared with LF prior to adjustment (Figs. 3a,b), the overall distribution of larger adjusted LF values closely resembled that before adjustment. The adjusted results are shown from this point forward since it accounts for the yearly variation in WWLLN detection efficiency and does not have a large impact on the overall lightning distribution.

To prevent interference from a few extreme cases, more representative lightning activity information was obtained using the normalized LF (Figs. 3e,f). For example, Fig. 3e represents a normalized LF composite analysis with respect to the vertical shear direction; its distribution (such as the distribution of the inner-core maximum and the relative maximum of the outer band) closely resembles that of the LF composite analysis. On closer inspection, the distributions exhibit minor differences, such as a portion of greater values in the LF or adjusted LF analysis on the upshear side near the 1-2 RMW. Further inspection revealed that these values were the result of a single extreme TC case in 2015 (figure not shown). Such phenomena are filtered in the normalized LF analysis, which more representatively depict the locations of strong and weak TC lightning distributions. Despite normalized composite analysis, the asymmetry of lightning distributions remains dominated by the vertical shear direction. By comparison, the lightning distributions in the motion-relative framework appear less asymmetrical (Fig. 3f).

\section{b. Lightning distribution and TC intensity}

Using the aforementioned method of composite analysis, adjusted LF and normalized LF were categorized into WTC (34-64 kt), MTC (64-96 kt), and STC ( $\geq 96 \mathrm{kt})$ according to Vmax values from the JTWC best track (Fig. 4). In the TCs of the adjusted LF analysis (Figs. 4a,c,e), the lightning distribution of weak TCs (Fig. 4a) is somewhat similar to that of the overall composite analysis (Fig. 3a). The maximum is in the downshear left in the inner core near the RMW; following the radius outward, larger adjusted LFs are transferred to the downshear right. The lightning distribution of moderate TCs (Fig. 4c) is relatively consistent. Areas with high adjusted LF values generally occur on the left-of-shear direction near the RMW, where lightning rarely occurs at more than 3 times the RMW. The lightning distribution of strong TCs (Fig. 4e) exhibits significant axial symmetry. A few extreme values occur 

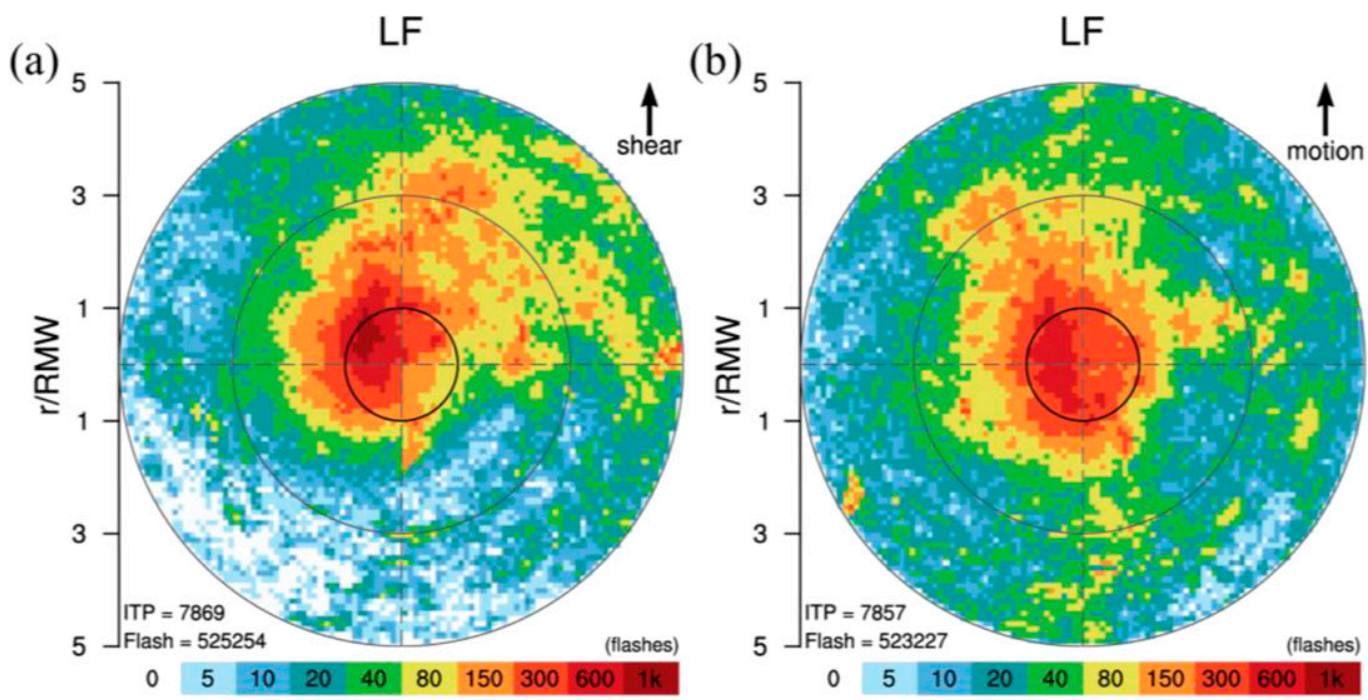

(c) Adjusted LF

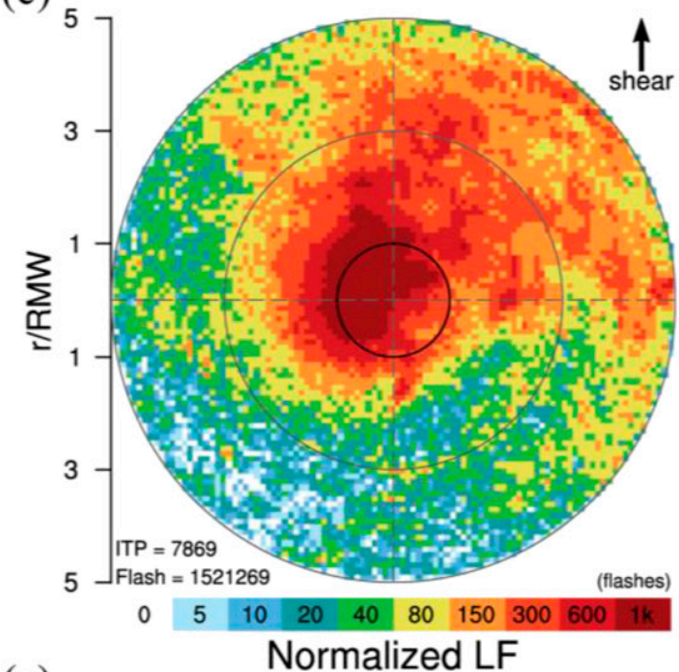

(e)

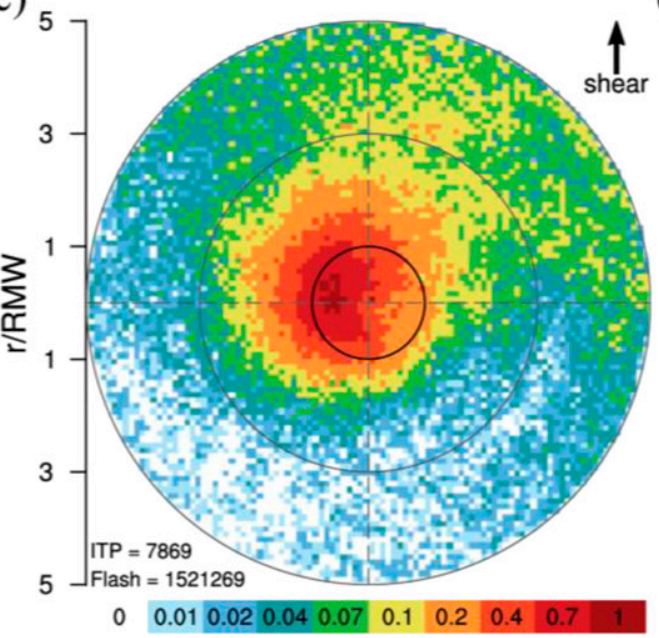

(d)

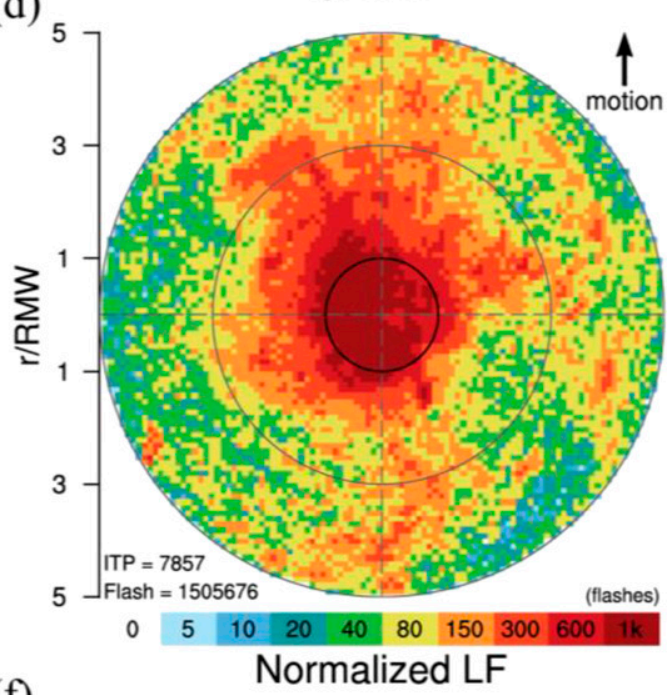

(f)

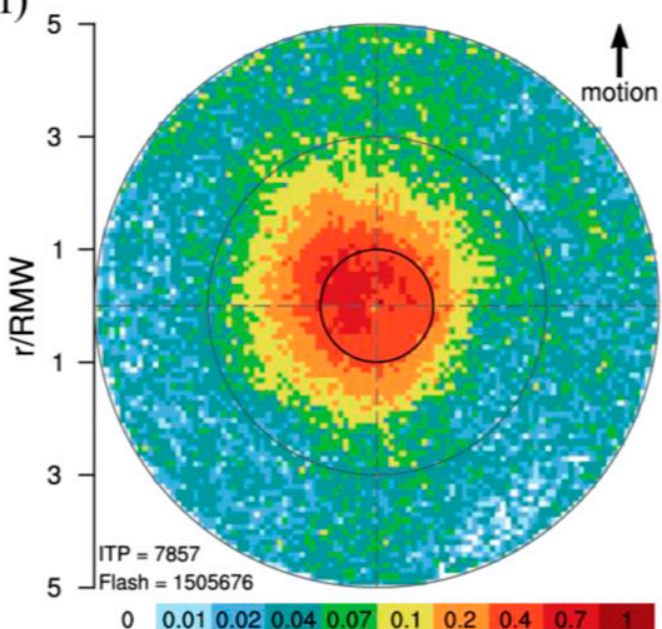

FIG. 3. The composites of (a) LF, (c) adjusted LF, and (e) normalized LF analyzed within 5 times the RMW for shear-relative coordinates. (b),(d),(f) As in (a), (c), and (e), but are for motion-relative coordinates. ITP represents the number of individual time periods, and FLASH is the total amount of lightning flashes in the analysis area. 

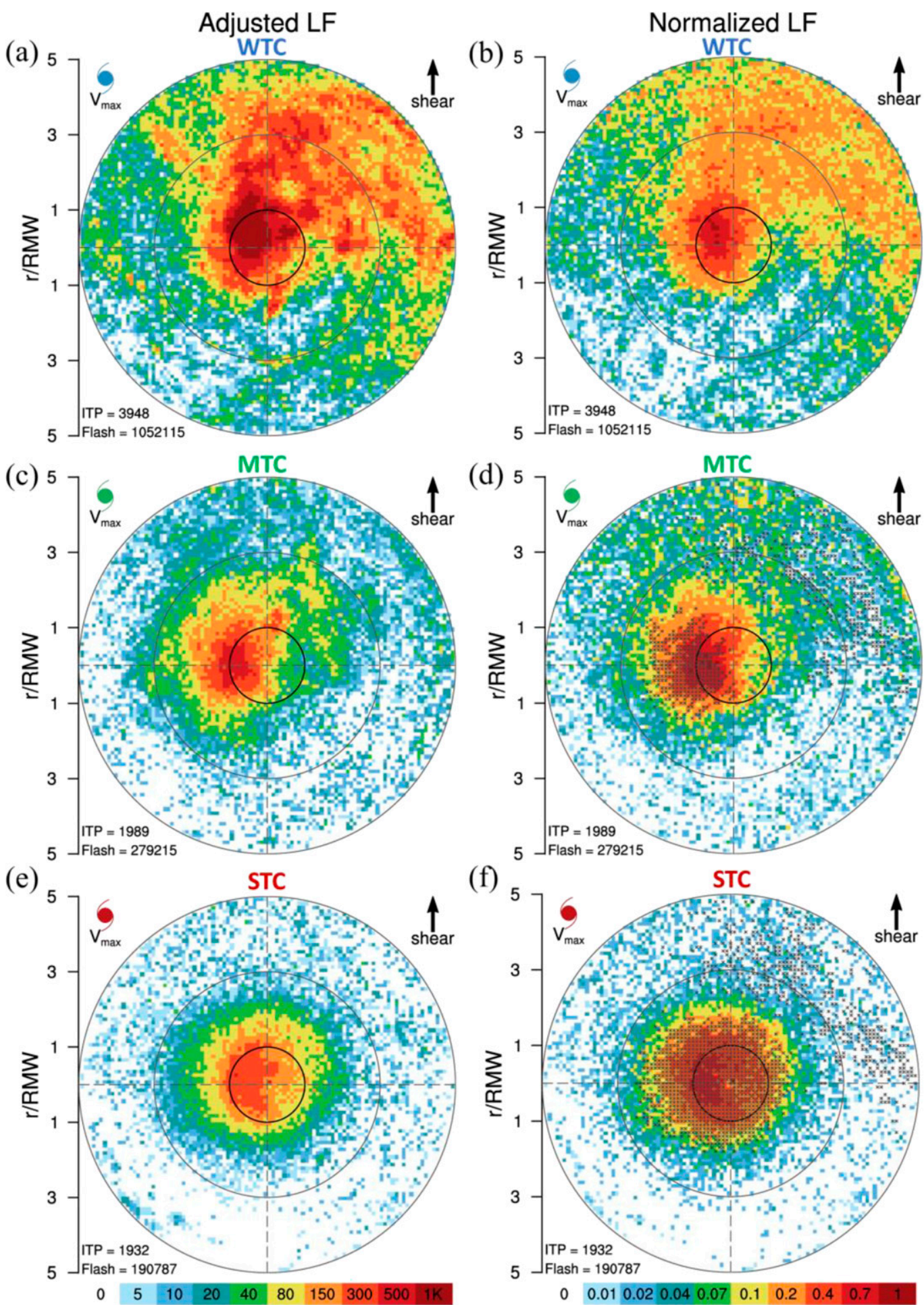

FIG. 4. As in Figs. 3c and 3e, but the data are classified according to TC intensity: (a),(b) weak; (c),(d) moderate; and (e),(f) strong TCs. The black stars in (d) and (f) represent the differences between (b) and (d) between (b) and (f), achieving the $99 \%$ confidence level for the Student's $t$ test. 
TABLE 3. Comparisons of lightning frequency (flash), lightning density $\left(10^{-3}\right.$ flashes $\left.\mathrm{km}^{-2} \mathrm{~h}^{-1}\right)$, radius of maximum wind (km), and the standard deviation values of normalized lightning frequency (NStd) in various classifications. 1R (5R) represents the lightning data within the RMW (5 times the RMW). In the columns for LD-1R and LD-5R, "b" represents the baseline group for the Student's $t$-test comparisons in each classification, and an asterisk indicates values that differ significantly from the baseline group's at the $95 \%$ confidence level. Furthermore, values in parentheses for LD-1R signify that the LD value is further adjusted through the random addition of a $\pm 10 \mathrm{~km}$ error to the original RMW estimate.

\begin{tabular}{|c|c|c|c|c|c|c|c|c|}
\hline Row No. & Category & ITP & RMW & FLASH-1R & FLASH-5R & NStd & LD-1R & LD-5R \\
\hline \multicolumn{9}{|c|}{ TC intensity } \\
\hline 1 & WTC & 3948 & 66.7 & 229975 & 1052115 & 0.17 & $6.3 *(7.7 *)$ & $1.1 *$ \\
\hline 2 & MTC & 1989 & 36.5 & 61062 & 279215 & 0.26 & $9.9 *\left(26.6^{*}\right)$ & $2.2 *$ \\
\hline 3 & STC & 1932 & 27.2 & 70873 & 190787 & 0.11 & $18.6 b(65.0 b)$ & $2.6 b$ \\
\hline \multicolumn{9}{|c|}{ VWS strength } \\
\hline 4 & WVS & 2857 & 47.7 & 88745 & 436659 & 0.10 & $9.9 *(36.0 \mathrm{~b})$ & $1.6^{*}$ \\
\hline 5 & MVS & 2436 & 51.5 & 163084 & 551140 & 0.17 & $13.0 \mathrm{~b}(25.4)$ & $2.0 \mathrm{~b}$ \\
\hline 6 & SVS & 2576 & 49.2 & 110081 & 534320 & 0.24 & $8.0 *\left(17.2^{*}\right)$ & $1.7^{*}$ \\
\hline \multicolumn{9}{|c|}{ TC intensity and VWS strength } \\
\hline 7 & WTC and WVS & 1355 & 65.8 & 40219 & 290896 & 0.11 & $3.1 *(3.5 *)$ & $0.8^{*}$ \\
\hline 8 & WTC and MVS & 1226 & 70.5 & 116806 & 391215 & 0.20 & $11.7 *\left(14.5^{*}\right)$ & $1.5^{*}$ \\
\hline 9 & WTC and SVS & 1367 & 64.3 & 72950 & 370003 & 0.19 & $4.8 *(5.9 *)$ & $1.1^{*}$ \\
\hline 10 & MTC and WVS & 626 & 37.7 & 15086 & 59421 & 0.14 & $8.9 *(40.7)$ & $1.9^{*}$ \\
\hline 11 & MTC and MVS & 607 & 37.2 & 21429 & 98298 & 0.19 & $11.5^{*}\left(16.6^{*}\right)$ & $2.5^{*}$ \\
\hline 12 & MTC and SVS & 756 & 34.8 & 24547 & 121495 & 0.28 & $9.3 *(22.9 *)$ & $2.4^{*}$ \\
\hline 13 & STC and WVS & 876 & 26.9 & 33440 & 86340 & 0.10 & $21.2 b(82.9 b)$ & $2.8 \mathrm{~b}$ \\
\hline 14 & STC and MVS & 603 & 27.3 & 24848 & 61627 & 0.15 & $17.3 *(56.6)$ & 2.6 \\
\hline 15 & STC and SVS & 453 & 27.7 & 12585 & 42821 & 0.15 & $15.4 *(41.6)$ & $2.2^{*}$ \\
\hline \multicolumn{9}{|c|}{ TC intensity change (lead time $-6 \mathrm{~h}$ ) } \\
\hline 16 & RW & 31 & 34.8 & 200 & 1948 & 0.14 & $5.3 *(10.2 *)$ & $1.1^{*}$ \\
\hline 17 & WE & 738 & 43.5 & 21762 & 83178 & 0.18 & $5.3 *\left(10.9^{*}\right)$ & $1.1 *$ \\
\hline 18 & ST & 2517 & 55.6 & 94885 & 542937 & 0.28 & $6.0 *(9.9 *)$ & $1.5^{*}$ \\
\hline 19 & IN & 3780 & 49.5 & 215617 & 785044 & 0.15 & $12.4 *\left(28.5^{*}\right)$ & $1.8 *$ \\
\hline 20 & RI & 709 & 28.3 & 28529 & 69092 & 0.12 & $20.4 b(96.9 b)$ & $2.9 \mathrm{~b}$ \\
\hline \multicolumn{9}{|c|}{ TC intensity change (lead time $0 \mathrm{~h}$ ) } \\
\hline 21 & RW & 69 & 41.1 & 371 & 5798 & 0.23 & $5.9 *(23.7 *)$ & $1.3^{*}$ \\
\hline 22 & WE & 883 & 41.6 & 36974 & 141599 & 0.18 & $9.8 *\left(19.6^{*}\right)$ & $1.9^{*}$ \\
\hline 23 & ST & 2498 & 55.0 & 132614 & 496750 & 0.17 & $8.6^{*}\left(16.6^{*}\right)$ & $1.5^{*}$ \\
\hline 24 & IN & 3661 & 51.2 & 160451 & 777517 & 0.20 & $9.4 *(22.1 *)$ & $1.7^{*}$ \\
\hline 25 & RI & 725 & 29.3 & 31339 & 80174 & 0.09 & $21.4 b(93.9 b)$ & $2.9 \mathrm{~b}$ \\
\hline \multicolumn{9}{|c|}{ TC intensity change (lead time $+6 \mathrm{~h}$ ) } \\
\hline 26 & RW & 96 & 31.0 & 1073 & 8590 & 0.14 & $4.5^{*}\left(12.1^{*}\right)$ & $1.4^{*}$ \\
\hline 27 & WE & 1072 & 39.6 & 39639 & 153704 & 0.24 & $12.5 *(30.4 *)$ & $2.1^{*}$ \\
\hline 28 & ST & 2603 & 55.7 & 120503 & 538711 & 0.19 & $8.4 *(19.9 *)$ & $1.6^{*}$ \\
\hline 29 & IN & 3387 & 51.3 & 168126 & 709867 & 0.17 & $9.8 *\left(25.3^{*}\right)$ & $1.7 *$ \\
\hline 30 & RI & 703 & 33.7 & 31149 & 102407 & 0.09 & $16.5 b(54.3 b)$ & $2.6 b$ \\
\hline
\end{tabular}

in the left-of-shear of the inner core, and overall lightning is concentrated in the TC center. Adjusted LFs exceeding 80 flashes are present within twice the RMW. When normalized LF is used to view the distribution of lightning activity (Figs. 4b,d,f), a region is apparent with a large range of normalized LFs greater than 0.4 in the downshear right of 3-5 times the RMW although the strongest normalized LF in the weak TC is located in the downshear left of the RMW (Fig. 4b). The largest normalized LF in the moderate TC is similar to the adjusted LF and is also located in the left-ofshear near the inner RMW. Overall, relatively greater normalized LFs $(>0.4)$ tend toward the downshear left near the inner core (Fig. 4d).
To evaluate the significant differences of normalized LF spatial distributions between WTCs and MTCs or STCs, grid points satisfying the Student's $t$ test $99 \%$ confidence level are also marked on the figure (e.g., Figs. 4d,f). This analysis indicated a significantly greater normalized LF in the left-ofshear area near the RMW in moderate TCs than in weak TCs, whereas normalized LF is significantly smaller in the downshear right of 3-5 times the RMW. The normalized LF distribution of strong TCs is somewhat similar to that of moderate TCs, although with an overall distribution more concentrated in the inner core and with relatively greater symmetry. Significance analysis indicated that, compared with weak TCs, the normalized LF of strong TCs within twice the RMW was 

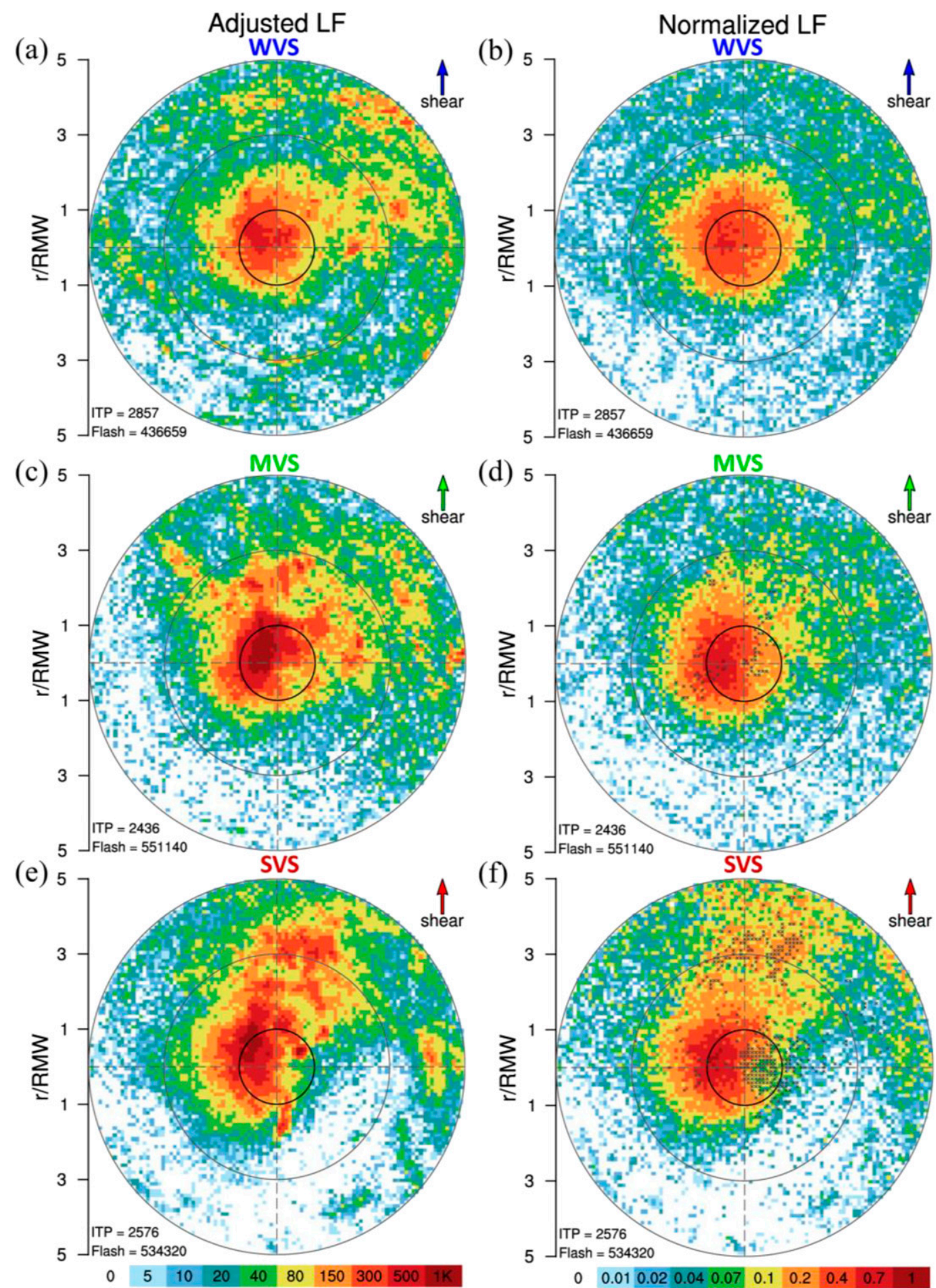

FIG. 5. As in Fig. 4, but the data are classified according to vertical wind shear strength: (a),(b) weak; (c),(d) moderate; and (e),(f) strong vertical wind shear. The black stars in (d) and (f) represent the differences between (b) and (d) and between (b) and (f), achieving the 99\% confidence level for the Student's $t$ test. 
significantly greater, whereas the normalized LF within the outer area at 3-5 times the RMW was significantly lesser.

Furthermore, to simply quantify and evaluate differences in lightning activity among different TC intensities, the ratio of adjusted lightning frequency per square kilometer to the number of analyzed ITPs was defined as average lightning density (LD). The LD-1R (LD-5R) values calculated within the range of the RMW ( 5 times the RMW) are summarized in rows $1-3$ of Table 3 . The LD-1R value of strong TCs $(18.6 \times$ $10^{-3}$ flashes $\mathrm{km}^{-2} \mathrm{~h}^{-1}$ ) is clearly statistically greater than those of weak and moderate TCs $\left(6.3\right.$ and $9.9 \times 10^{-3}$ flashes $\left.\mathrm{km}^{-2} \mathrm{~h}^{-1}\right)$. The LD-5R value of strong TCs is also clearly statistically larger than those of weak and moderate TCs. Furthermore, to assess whether the differences in LD values among the three categories are influenced by the RMW estimated error, the LD values are also calculated through the random addition of $\pm 10 \mathrm{~km}$ (based on the RMW estimated error from Kossin et al. 2007) to the original RMW values for each ITP. Note that if the random assignment of the RMW value is less than $0 \mathrm{~km}$, lightning samples related to these TC cases were removed from the LD calculations as shown in Table 3. The results are also consistent, with strong TCs exhibiting greater LD-1R $(65.0 \times$ $10^{-3}$ flashes $\mathrm{km}^{-2} \mathrm{~h}^{-1}$ ) value and for weak TCs revealing lesser LD-1R $\left(7.7 \times 10^{-3}\right.$ flashes $\left.\mathrm{km}^{-2} \mathrm{~h}^{-1}\right)$ value around the inner core of the storm.

\section{c. Lightning distribution and VWS strength}

Using a similar analytical method, VWS was divided into WVS (0.1-10 kt), MVS (10-17 kt), and SVS ( $>17 \mathrm{kt})$ according to shear strength, and lightning distributions for these three VWS strengths were observed. In the composite analysis of adjusted LF, maximum adjusted LF appears in the downshear left within or just outside the RMW (Figs. 5a,c,e). However, in stronger VWS strength categories, high adjusted LFs also shifted more outward to the downshear side; in the outer band areas (3-5 RMW) with SVS, high adjusted LFs shift toward the downshear right. In WVS, normalized LF exhibits significantly greater axial symmetry (Fig. 5b). Following an increase in VWS strength, high normalized LF in the inner core shifts to the left-of-shear, and normalized LF in the outer band area also increases gradually on the downshear side (Figs. 5d,f). Compared with a WVS environment, the Student's $t$ test $99 \%$ confidence level for MVS had fewer samples, most of which were distributed near the downshear right of the inner core (Fig. 5d). The difference between SVS and WVS was significantly greater, with the primary difference occurring in the right-of-shear near the inner core; the outer downshear right also exhibited areas with relatively substantial differences (Fig. 5f). This result is consistent with the finding of Corbosiero and Molinari (2003), which revealed increasing vertical shear is manifested by an increase in the azimuthal asymmetry in the inner core (inside the RMW) peaking toward the left of shear (reflected by a reduction right of shear) and an increase of azimuthal asymmetry peaking downshear right at large radii.

To simply quantify and evaluate differences in lightning activity among the aforementioned condition categories, the LD-5R values were calculated and then normalized by the maximum quantities for comparison (Fig. 6). Detailed LD-5R
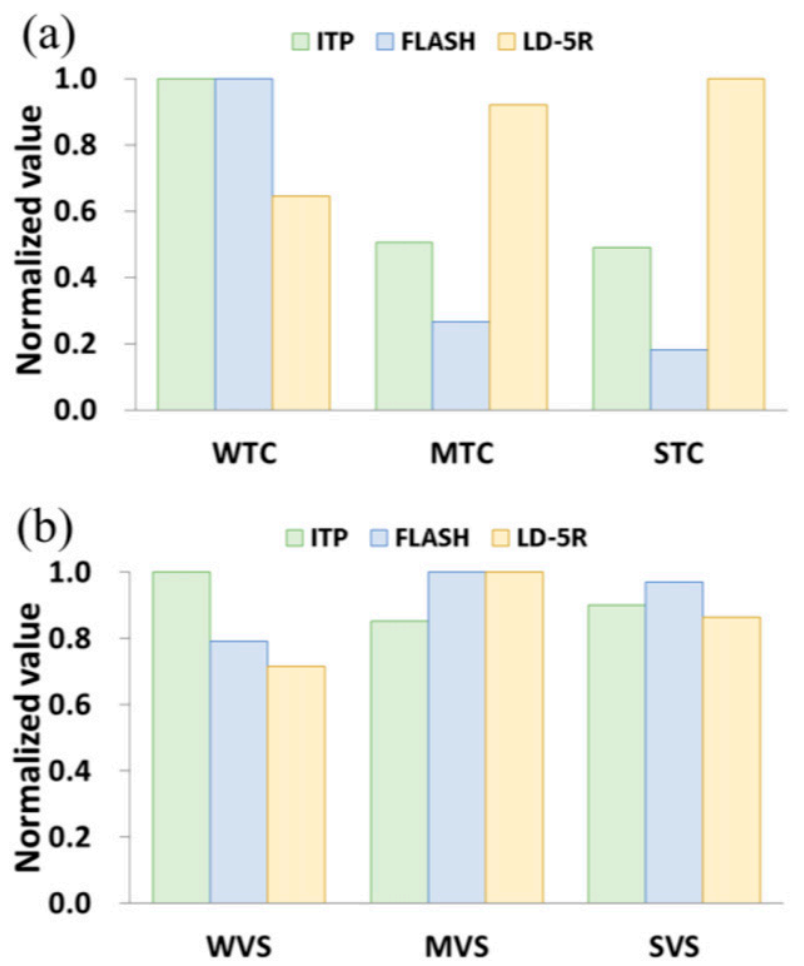

FIG. 6. Comparisons of ITP, FLASH, and LD-5R using the normalized value for (a) TC intensity and (b) strength of vertical wind shear. LD-5R is defined by the number of flashes per $\mathrm{km}^{2}$ within 5 times the RMW divided by the number of ITPs.

values of each classification are also listed in Table 3. For instance, Fig. 6a shows a comparison of normalized ITP, FLASH, and LD-5R values in WTC, MTC, and STC conditions. Clearly, the ITP and FLASH values of WTC are the largest, whereas the LD-5R value is smallest; however, MTCs and STCs exhibit greater LD-5R values in relatively lower ITP and FLASH values than WTCs do. In summary, WTC exhibits greater samples of lightning occurrence but lower average LD-5R per unit of time. Following increases in TC intensity, overall lightning occurrence time decreases and LD-5R increases. In a comparison of the WVS, MVS, and SVS environments (Fig. 6b), although the WVS environment exhibited the greatest number of ITPs, it exhibited the lowest FLASH and LD-5R values. In MVS and SVS conditions, although the ITP value was smaller than that in WVS condition, these conditions exhibited the greater FLASH and LD-5R values. The LD-5R values per unit of time for the lightning events are greater, and the LD-5R value of MVS is clearly shown to be statistically larger than those of WVS and SVS (rows 4-6 of Table 3).

\section{d. Lightning characteristics of the nine types of VWS and TC intensity}

TC lightning was further divided into nine types in composite analysis and is presented using normalized LF (Fig. 7). In WTC and WVS conditions (Fig. 7a), overall lightning distribution was more widely dispersed. Excluding the upshear left, all other quadrants exhibited normalized LF greater than 


\section{Normalized LF}

(a)

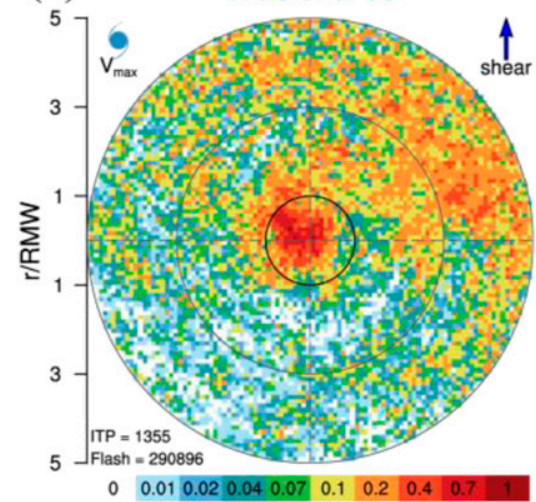

(d)

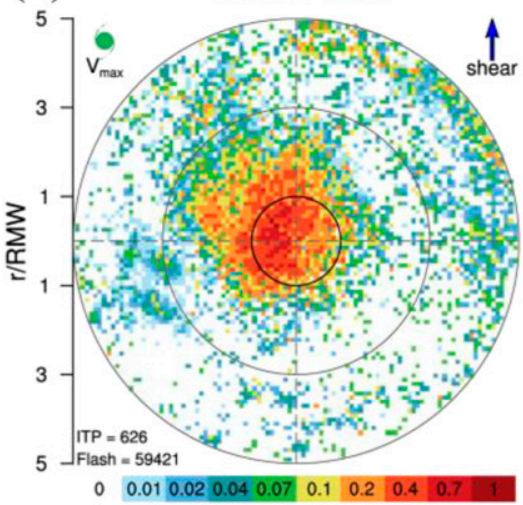

(g)

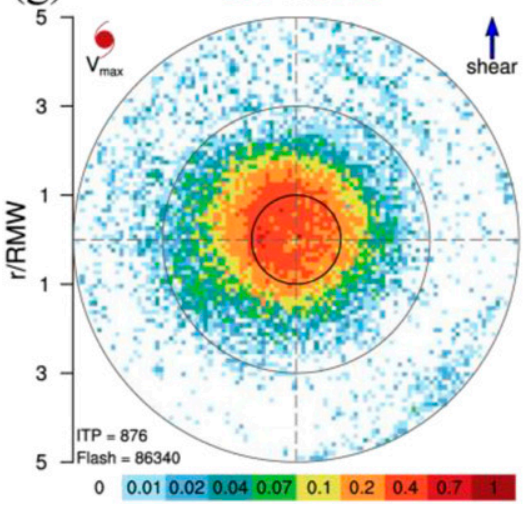

(b)

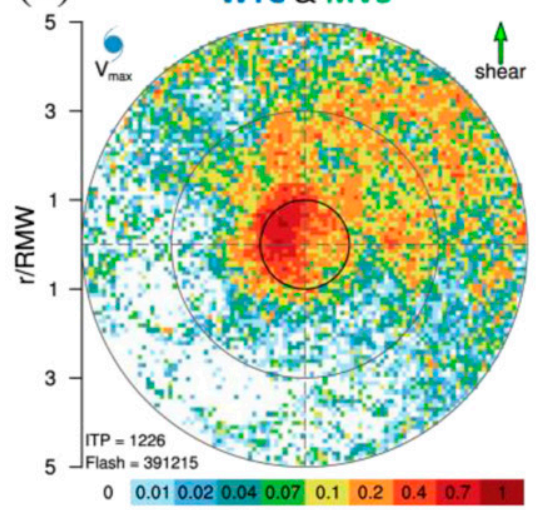

(e)

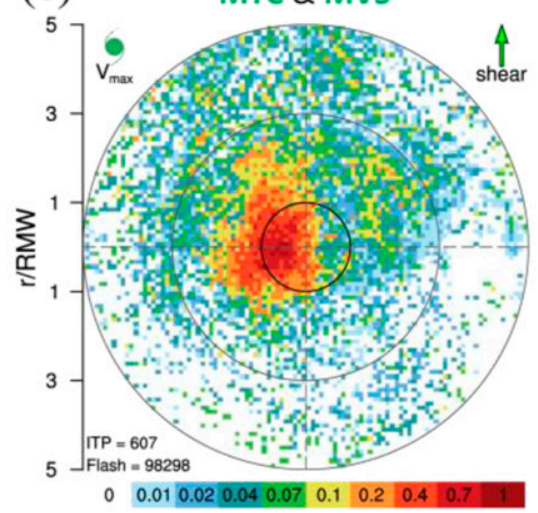

(h)

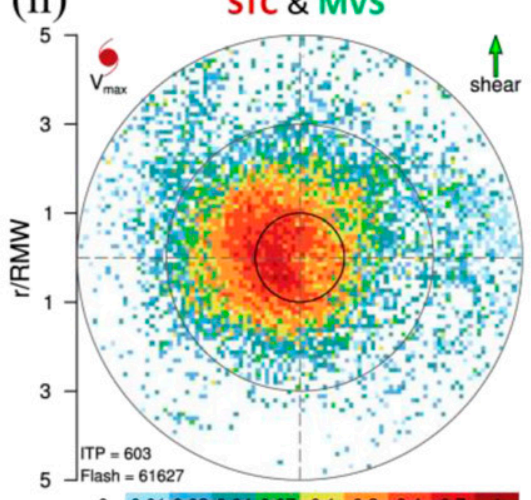

(c)

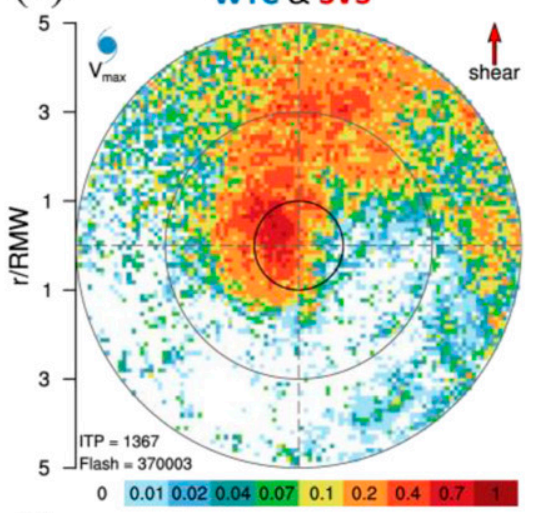

(f)

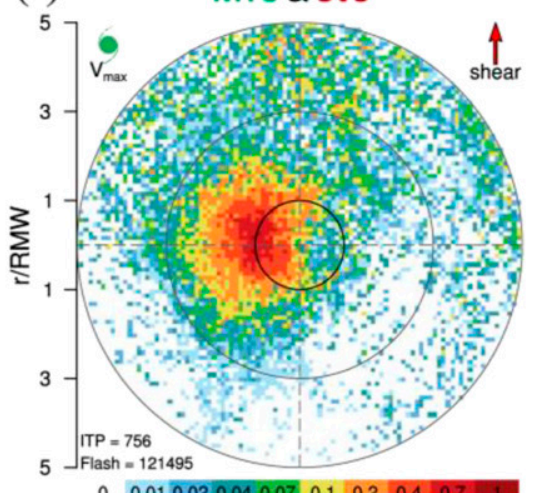

(i)

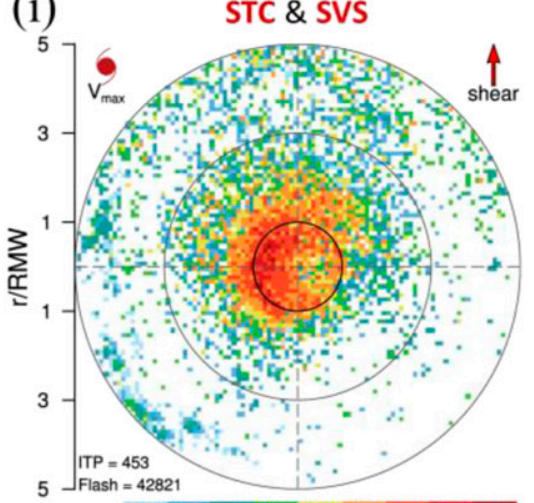

FIG. 7. As in Fig. 3e, but the data are further classified according to (from top to bottom) weak to strong TC intensity and (from left to right) weak to strong vertical wind shear.

0.4. However, the inner-core area (within the RMW) was highly symmetrical and uniform, and a higher proportion of high normalized LFs in the outer band (3-5 RMW) occurred in the downshear right. As vertical shear strength increased, the distribution of high normalized LFs gradually shifted toward the left-of-shear direction in the inner core, and more lightning occurred downshear (Figs. 7b,c). The distribution of LF in moderate TC for various VWS strengths is shown in
Figs. 7d, 7e, and 7f. For three VWS strengths, the outer band exhibited normalized LFs that were not excessively high $(<0.4)$, and inner-core lightning was relatively concentrated and evenly distributed within the RMW in WVS. As vertical shear increased, inner-core lightning also shifted to the left-ofshear outside the RMW. In STC conditions, lightning distribution was, by comparison, the most concentrated and symmetrical (Figs. 7g-i). Lightning in WVS conditions occurred mostly 

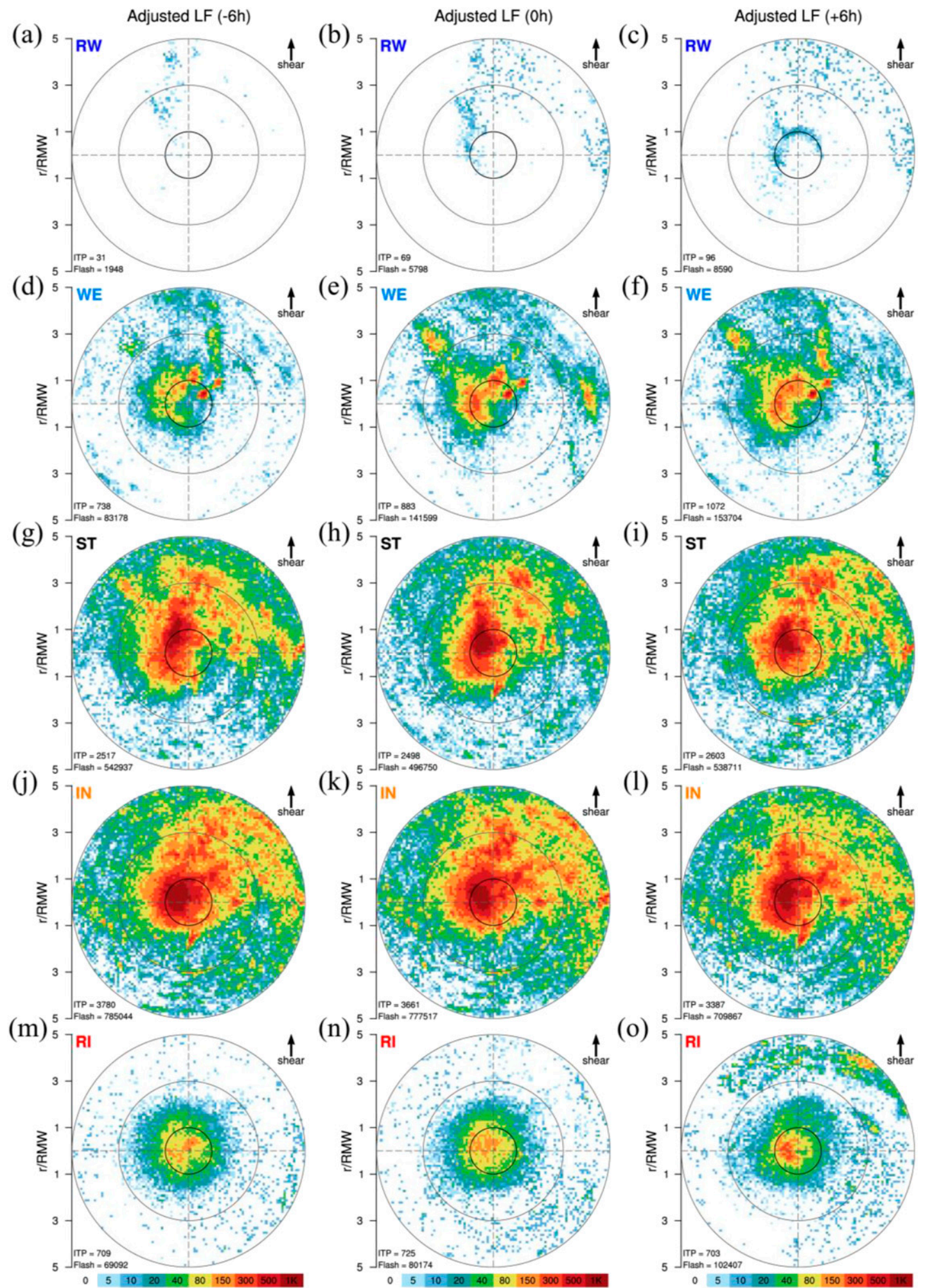

FIG. 8. The composites of adjusted LF classified according to TC intensification rates and lead times: (a)-(c) rapidly weakening; (d)-(f) weakening; (g)-(i) in a steady state; (j)-(l) intensifying; and (m)-(o) rapidly intensifying. The lead times are (left) -6 , (center) 0 , and (right) $+6 \mathrm{~h}$. 
within twice the RMW and exhibited very high symmetry. As VWS increased, TC lightning shifted slightly in the left-ofshear direction. Even in SVS conditions, inner-core lightning exhibited a uniform but nonetheless slightly asymmetric distribution near the RMW.

Overall, lightning distribution for WTC in an SVS environment (Fig. 7c) exhibited the greatest asymmetry, and a high proportion of inner-core lightning occurred in the downshear left. In the outer band, lightning occurred primarily in the downshear side. By contrast, lightning distribution for STC in a WVS environment (Fig. 7g) exhibited the greatest axial symmetry, and almost all lightning flashes occurred in areas close to the inner core. The aforementioned results are consistent with a studies by Chen et al. (2006) and Wingo and Cecil (2010) comparing TC intensity and VWS strength with precipitation asymmetry. In their study, weaker TCs and stronger VWS were accompanied by precipitation distributions that were farther from the TC center; conversely, distributions were closer to the TC center during stronger TCs and weaker VWS. Composite analyses derived from aircraft, lightning, and satellite observations show that environmental vertical shear is the dominant factor governing the development of azimuthal wavenumber-1 convective asymmetries of TCs (Corbosiero and Molinari 2002, 2003; Chen et al. 2006; Rogers et al. 2013, 2015, 2016; Wadler et al. 2018). On the basis of the metric from Reasor et al. (2013), the standard deviation values of normalized LF (NStd) for the 72 azimuth points at the RMW were calculated (rows of 7-15 of Table 3). The variable NStd could easily be applied to determine the asymmetry of inner-core lightning distribution; namely, the larger the NStd value is, the more asymmetric the TC lightning distribution is. Results indicate that the stronger the TC intensity is and the weaker the VWS strength is, the smaller the NStd values are, which means a more symmetric inner-core lightning distribution. An exception is noted for the weaker TCs whose NStd values in three vertical shear categories $(0.11,0.20,0.19)$ are smaller than those of moderate TCs $(0.14,0.19$, $0.28)$. In general, for weaker TCs, the closed inner-eyewall may not be built completely, and this increases the uncertainty of detecting the storm center's location. Furthermore, deep convection can also occur randomly around the storm. These effects might increase the symmetry of TC inner-core lightning distribution.

\section{TC lightning distribution associated with $\mathrm{TC}$ intensity change}

\section{a. Analysis of adjusted LF and TC intensity change}

As described in the research method, TC intensity change was divided into five categories (RW, WE, ST, IN, RI) according to near-center Vmax value provided by the JTWC best track. These five categories were combined with three lead times $(-6,0,+6 \mathrm{~h})$ to produce 15 combinations of adjusted LF composite maps (Fig. 8). Among these maps, too few RW samples were obtained for the results to be statistically significant; thus, those results are not elaborated upon here (Figs. 8a-c). Most samples were categorized as ST (Figs. 8g-i) and IN (Figs. 8j-1) types. In a comparison of lightning differences between these two categories, excluding a greater number of IN samples, overall lightning distribution was highly similar between the two types.

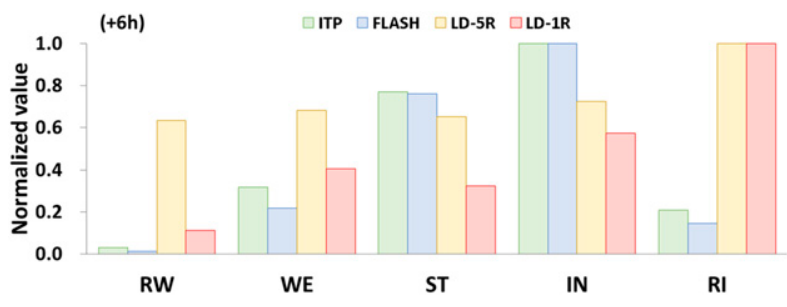

FIG. 9. As in Fig. 6, but for five types of TC intensification rates at lead times of $+6 \mathrm{~h}$, also including the LD-1R value for comparison.

Closer inspection of lightning distribution near the inner core, however, revealed that the adjusted LF maximum for the IN category (Figs. 8j-1) was closer to the TC center than that for the ST category (Figs. 8g-i). Although the WE (Figs. 8d-f) and RI (Figs. 8m-o) categories exhibited similar sample sizes, patterns of lightning distribution were significantly different between the two types. In the WE category, high adjusted LFs were distributed mostly on the ring of the RMW, and sporadic lightning also occurred in the outer band; in RI, lightning was clearly concentrated within the RMW, and almost no lightning flashes occurred in the outer band (excluding $+6 \mathrm{~h}$ downshear right).

These spatial distributions of lightning (using $+6 \mathrm{~h}$ as the basis) were normalized and quantified for comparison (Fig. 9). As previously mentioned, the ITP and FLASH values for the IN category were greatest. Although the ITP and FLASH for the ST category were significantly lower, the LD-5R was almost the same as that of IN. The ITP and FLASH values of the RI type were lower than others (except RW), but the LD, especially LD-1R (LD within RMW), for the RI type was the greatest. Statistically significant differences among the five categories for the LD-1R and LD-5R values were further examined: Both the LD-1R and LD-5R values of RI type were significantly larger than the values for other types (rows 26-30 of Table 3). These results are consistent with the findings of Rogers et al. (2013) that, using airborne Doppler radar, showed convective bursts tend to be located inside the RMW for intensifying TCs (similar to IN and RI cases in this study), and at or outside the RMW for steady-state TCs (similar to ST cases in this study).

\section{b. Analysis of normalized LF and TC intensity changes}

Similarly, normalized LF was divided into 15 combinations (Fig. 10) using TC intensity change and lead times. Because the RW sample size was too small, normalized LF strength exhibited little distinguishability (Figs. 10a-c). A similar distribution pattern existed between ST and IN (Figs. 10g-1), and some differences were observed within the distribution of inner-core maximum locations. The IN category was closer to the TC center, and the outer area of the ST exhibited more normalized LFs that exceeded 0.1. Furthermore, to assess the statistical significance of differences, the location for the Student's $t$ test $99 \%$ confidence level is also indicated on the figures (all compared with a benchmark of ST). Because ST and IN distribution patterns were extremely similar, few data achieved more than a $99 \%$ significant difference; excluding the 

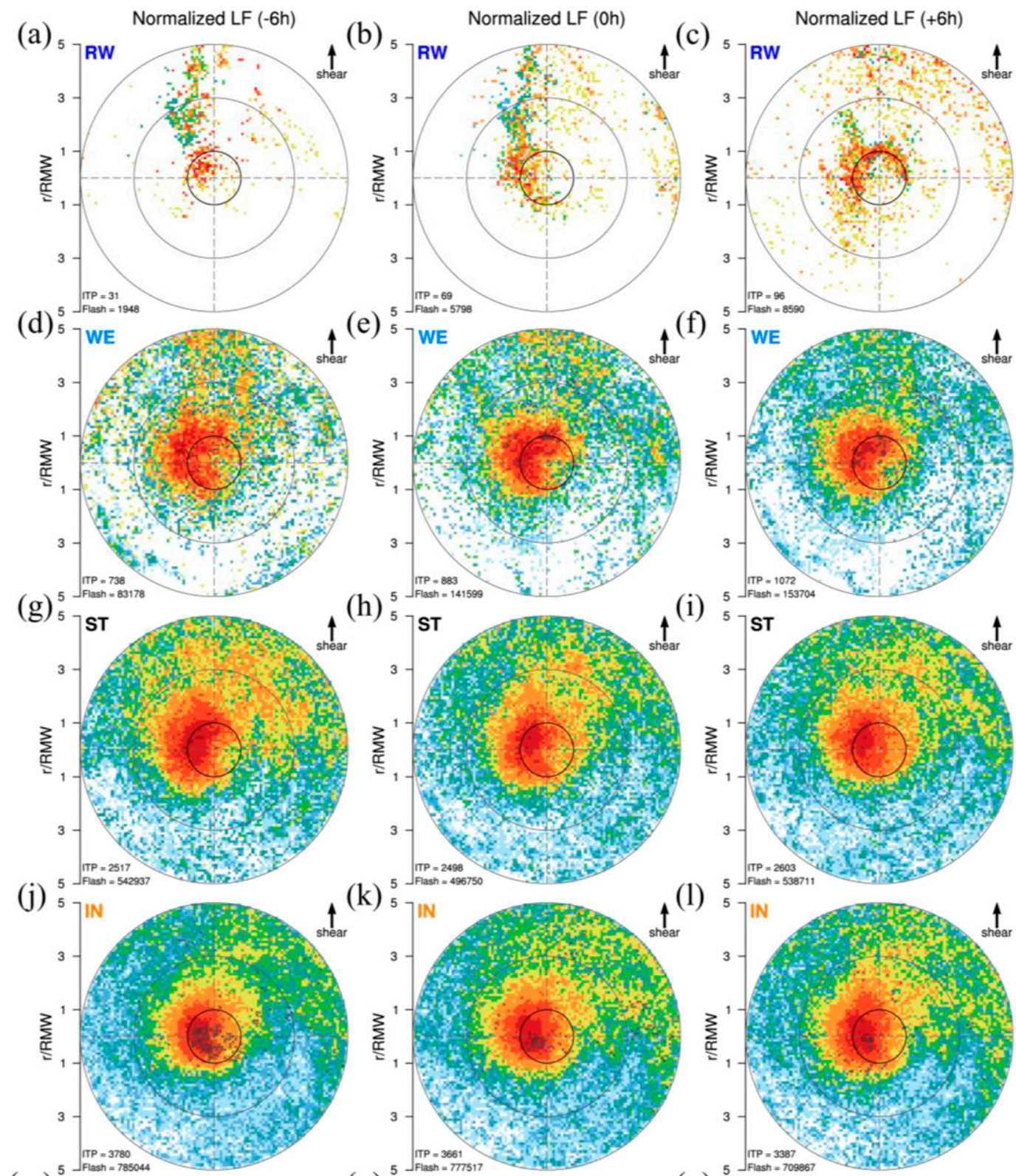

(i)
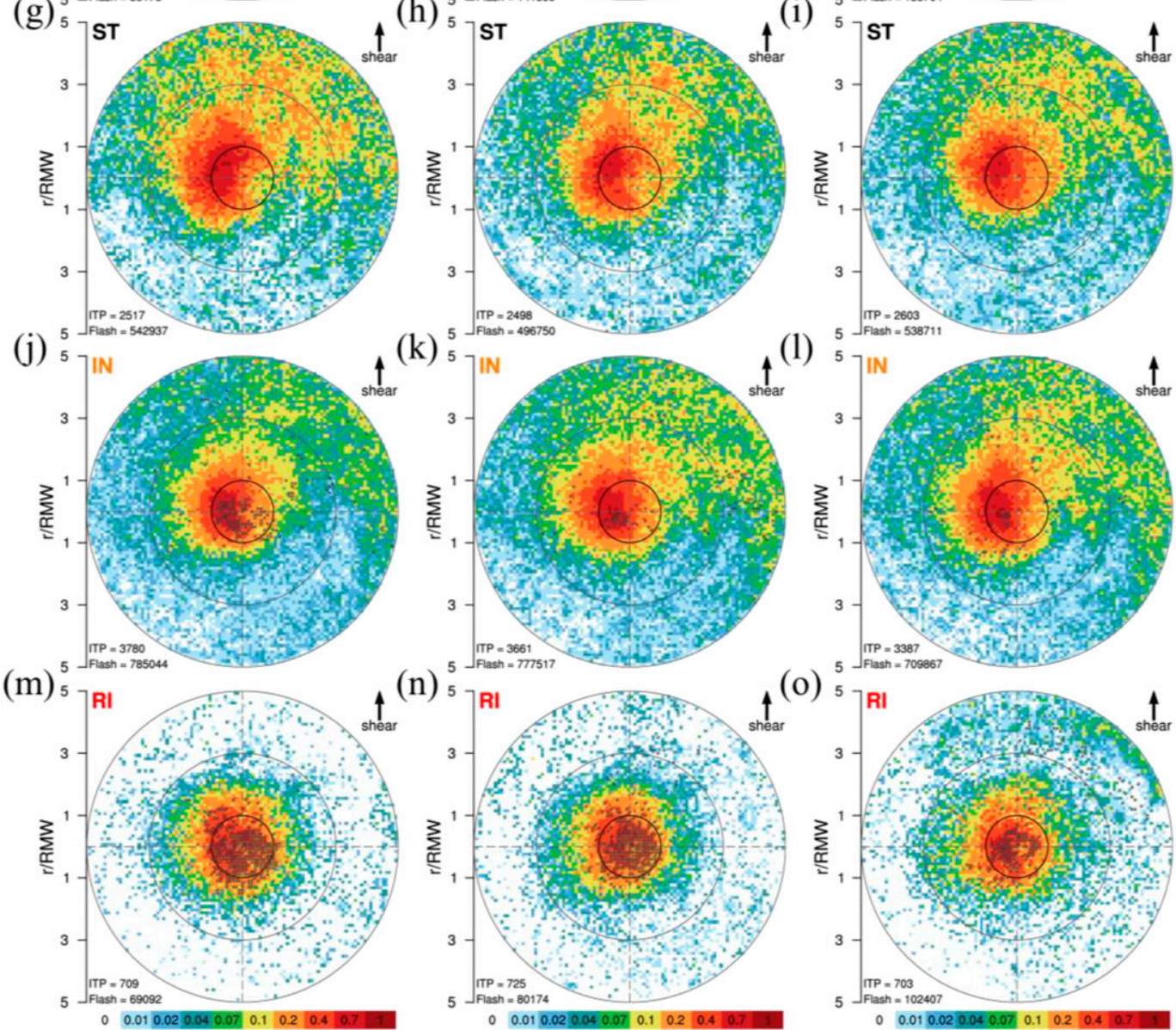

FIG. 10. As in Fig. 8, but for normalized LF. The black stars represent the differences between steady-state-type TCs and other types achieving the $99 \%$ confidence level for the Student's $t$ test. 


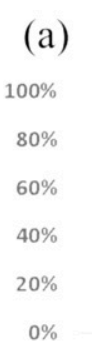

(c)

$100 \%$
$80 \%$
$60 \%$
$40 \%$
$20 \%$
$0 \%$

RW
Percentage of Adjusted LF

$$
\text { ロ0-1 RMW } \square \text { 1-5 RMW }
$$

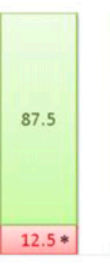

RW

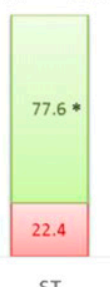

ST

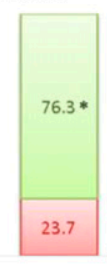

IN

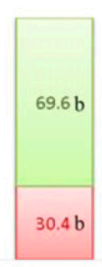

RI (b)

$100 \%$ $\square \mathrm{DR} \square \mathrm{DL}$ 口UL $\square \mathrm{UR}$

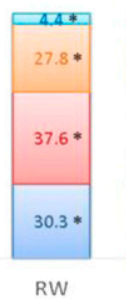

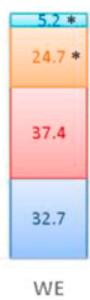

WE

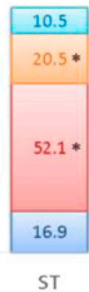

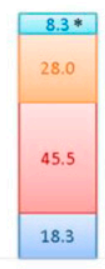

IN

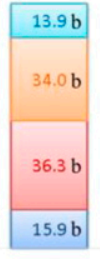

RI
$100 \%$
$80 \%$
$60 \%$
$40 \%$
$20 \%$
$0 \%$

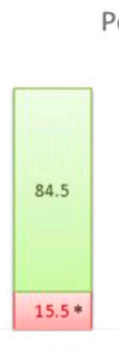

RW
Percentage of Normalized LF

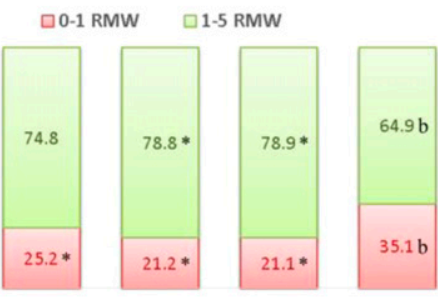

WE

IN

RI

Percentage of Normalized LF within RMW $\square \mathrm{DR} \square \mathrm{DL} \square \mathrm{UL}$ 口UR
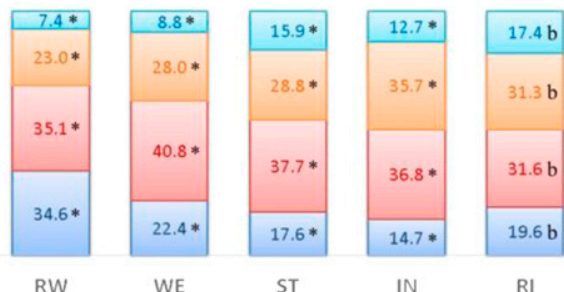

RI

FIG. 11. The percentages for (a),(c) adjusted LFs and (b),(d) normalized LFs in various (a),(b) radial distributions and (c),(d) azimuth distributions within the RMW corresponding to the five TC-intensification-rate types at the lead times of $+6 \mathrm{~h}$. The two-color bars in (a) and (b) represent the radial ranges relative to RMW, and the four-color bars in (c) and (d) represent the quadrants relative to the direction of vertical wind shear. DR, DL, UL, and UR represent downshear-right, downshear-left, upshear-left, and upshear-right quadrants, respectively. In the figure, " $b$ " represents the baseline group for the Student's $t$-test comparisons in each quadrant, and the asterisk indicates the respective values differ significantly from those in the baseline group at the $95 \%$ confidence level.

increased concentration in the inner core within the RMW for $-6 \mathrm{~h}$, these data were sporadically distributed throughout the entire analysis range. Greater normalized LFs in the WE category exhibited an arc distribution in the downshear left near the RMW (Figs. 10d-f), and -6 h exhibited greater normalized LF distribution in the downshear side of the outer band. Compared with the ST category, statistical differences in the WE category were also not noticeable, and only a few sporadic positions achieved 99\% statistical significance.

The RI group exhibited relatively different characteristics (Figs. 10m-o). The normalized LF distribution was particularly concentrated in the inner-core area, and almost no normalized LF values greater than 0.1 occurred in the outer band (3-5 RMW). Furthermore, compared with ST, statistical differences in the RI category were significantly greater and more concentrated and were almost all located within the range of the RMW, closer to the upshear and upshear-left sides. Differences among the three lead times were minimal. A lead time of $+6 \mathrm{~h}$ implicitly predicts the possible future TC intensity changes, and subsequent related analyses used the lead time of $+6 \mathrm{~h}$.

\section{c. Concentration and symmetry of lightning distribution}

To more accurately distinguish differences between the spatial distributions of lightning for each category, a quantified chart was employed to present the degrees of concentration and symmetry of distributions (Fig. 11). Using $+6 \mathrm{~h}$ data $(6 \mathrm{~h}$ after the time of lightning detection) as the basis, Figs. 11a and $11 \mathrm{~b}$ present the radial percentages for adjusted LF and normalized LF, respectively, at various distances from the TC center. Although the adjusted LF and normalized LF percentages are not identical in every category, overall differences and trends are the same. A larger red histogram indicates that lightning is more concentrated within the RMW. Clearly, for the RI category, radial percentages exceed $30 \%$ only for $0-1$ RMW, corresponding with Figs. 8 and 10. In Figs. 11c and 11d, the means of adjusted LF and normalized LF within the RMW were calculated according to the four quadrants of the vertical shear direction. Cool colors indicate the right-of-shear direction and warm colors represent the left-of-shear direction. The bottom two histograms are in the downshear direction, and the top two histograms are in the upshear direction. An analysis of the figures clearly reveals two distinct, common characteristics: Inner-core lightning was mostly located in the 1) left-ofshear and 2) downshear direction areas; moreover, lightning distribution in the RI category exhibited the most uniform four-azimuth distributions, although the proportion in the leftof-shear direction was slightly higher than that in the right-ofshear direction. Therefore, calculations of the radial mean and azimuth mean revealed a distinct characteristic: When RI occurs, the lightning distribution of TC is usually concentrated in the inner-core area, and azimuth distribution is also relatively symmetrical. Notably, this characteristic of RI type lightning distribution also achieved more than a $95 \%$ significant confidence level as compared to most of the other types. These analyses are also similar with observational composite results using airborne Doppler radar shown in Rogers et al. (2013) and Wadler et al. (2018), they revealed that intensifying TCs have 
more lightning in the left-of-shear, upshear, and inside the RMW than steady-state TCs.

\section{d. Environmental conditions that contribute to TC inner-core lightning distribution}

According to the composite analysis, RI TCs exhibit more concentrated and symmetrical inner-core lightning distribution than other types of TC do. Thus, the concentration rate and the symmetry of the inner-core lightning distribution for each ITP were analyzed; in Fig. 12, the $y$ axis represents LD-1R, which indicates the concentration rate of inner-core lightning distribution, and the $x$ axis represents 1/LStd, which represents the symmetry of the inner-core lightning distribution. LStd is similar to NStd, except that the standard deviation values of the adjusted LF for the 72 azimuth points at the RMW were calculated. It has been examined that the LStd better represents the symmetry of lightning distribution for each ITP. The average values of LD-1R and 1/LStd for five categories were also compared. Results show that the RI category exhibited greater values for LD-1R and 1/LStd than other categories did. In particular, both the average LD-1R and 1/LStd values in the RI category were statistically greater than those in the IN category, indicating that the lightning distribution in the RI category is more concentrated and axisymmetric. Notably, the concentration and symmetry results obtained were directly calculated from individual ITPs in which the LD-1R values exceed $0.1 \times 10^{-3}$ flashes $\mathrm{km}^{-2} \mathrm{~h}^{-1}$; the results obtained in section $4 \mathrm{c}$ originated mainly from the composite results of each classification.

Next, the environmental conditions were examined to distinguish which factors or mechanisms contribute to greater LD-1R and 1/LStd values (upper right of Fig. 12). To address this issue, samples were subjectively divided into four quadrants using the LD-1R value of $30.0 \times 10^{-3}$ flashes $\mathrm{km}^{-2} \mathrm{~h}^{-1}$ and the 1/LStd value of 2.0. Q1 would represent symmetric storms with larger lightning densities inside the RMW, Q2 would represent less symmetric storms with larger lighting densities inside the RMW, Q3 would represent less symmetric storms with smaller lighting densities inside the RMW, and Q4 would represent symmetric storms with smaller lighting densities inside the RMW. The average values for six environmental conditions from the SHIPS dataset (SHRD, D200, RHLO, MPI, SST, OHC) were then compared for the four quadrants. Figure 13 shows the boxplots of six environmental conditions from samples belonging to four quadrants, and statistical significance of their mean values is also labeled. Results show that Q1 exhibits smaller SHRD value and greater MPI value than do other quadrants, a greater D200 value than that in Q2 and Q3, and a greater SST value than that in Q3 and Q4. However, the RHLO and OHC values do not differ significantly with those in other quadrants. These results clearly imply that the better oceanic conditions could supply more enthalpy to the storm (greater MPI and SST) as well as environmental flow patterns that provide upper-level ventilation (greater D200) and vertical structure coherence (smaller SHRD) contribute a more concentrated and symmetric TC inner-core lightning distribution. Note that the $\mathrm{OHC}$ data used here are the climatology values, not daily data such as MPI and

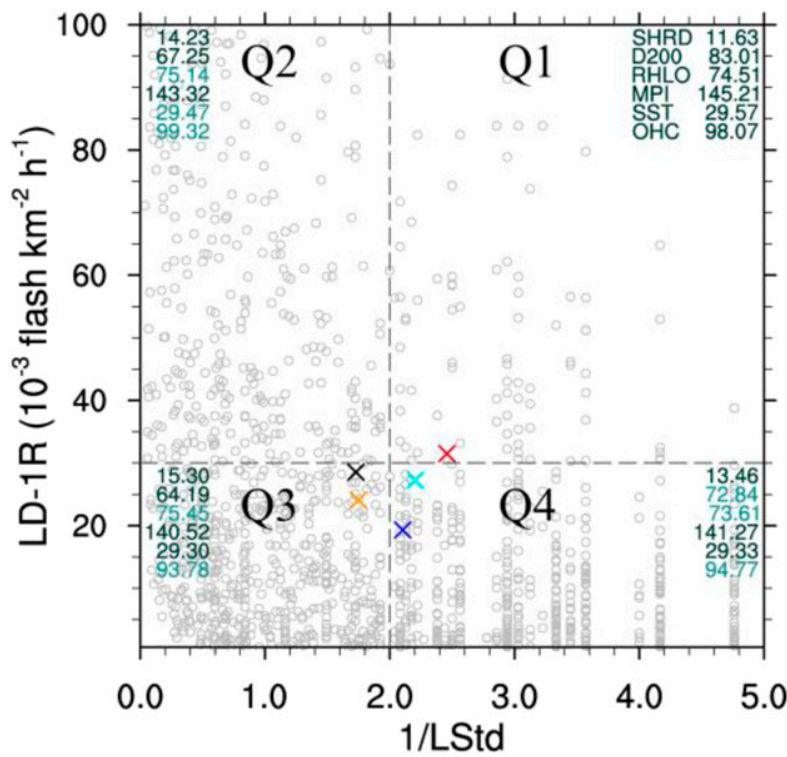

FIG. 12. Scatterplot of $1 / \mathrm{LStd}$ and LD-1R values for the 5th and 95th percentiles of LD-1R values. The $x$ axis represents a measure of azimuthal symmetry of lightning, and the $y$ axis represents a measure of the concentration of lightning near the center. Open circles represent the individual values of each ITP, while red, orange, black, cyan, and blue crosses represent the average values for RI, IN, ST, WE, and RW categories, respectively. Dashed lines are subjectively chosen to separate samples into four quadrants. Average values for environmental conditions from SHIPS data on samples in four quadrants are also labeled for references. The dark green numbers in Q2-Q4 signify that the respective values differ significantly from those in Q1 at the 95\% confidence level; light green numbers indicate that respective values do not differ significantly from those in Q1.

SST values, which might cause the relationship to be inconsistent with those for the other two oceanic conditions.

\section{Discussion and conclusions}

This study employed WWLLN lightning data, TC data from the JTWC best track, and NCEP-FNL wind field data to analyze 230 TCs that occurred from 2005 to 2017 and examined characteristics of RMW-relative lightning spatial distribution according to TC intensity, VWS, motion direction, and TC intensity change. In principle, the spatial distribution of TC lightning closely resembles that of strong convection. The effect of VWS direction is significantly greater than that of motion direction: Stronger VWS leads to increased asymmetry in lightning distribution, strong lightning occurrences shift in position toward the downshear side and the outer band, and increases in average LD (Corbosiero and Molinari 2002, 2003; Abarca et al. 2011; DeMaria et al. 2012; Stevenson et al. 2014, 2016; Fierro and Mansell 2017). When TC intensity is weaker, lightning activity increases and average LD is lower (Abarca et al. 2011; DeMaria et al. 2012; Zhang et al. 2015; Stevenson et al. 2018; Wang et al. 2018). Situations where weak TC is in a moderate-to-strong VWS environment exhibit a higher proportion of outer-band lightning with greater asymmetry. 
(a)
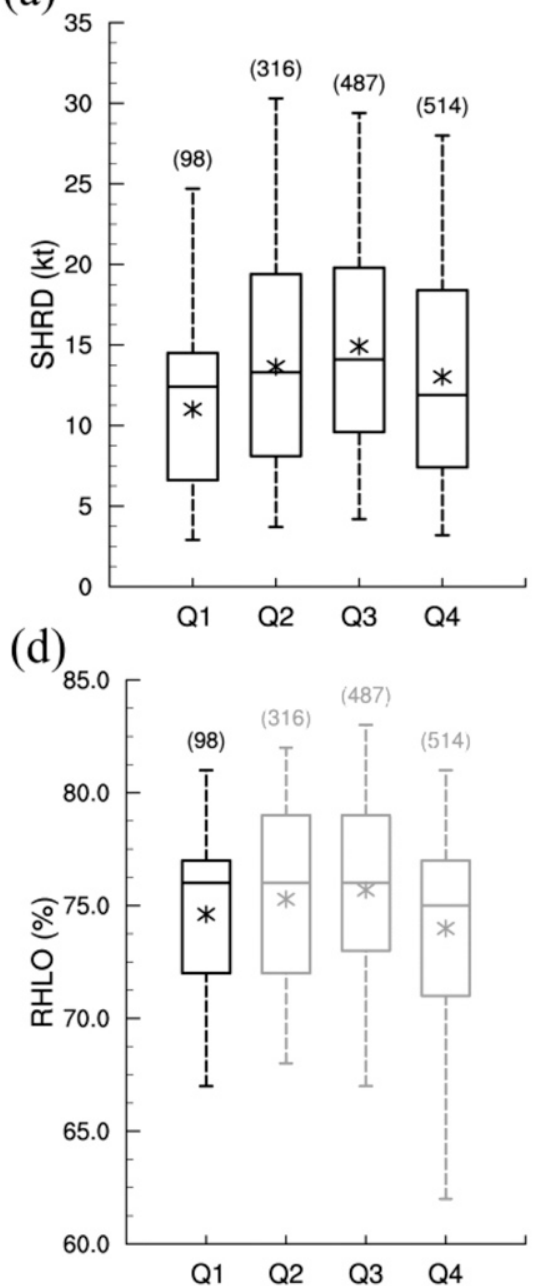

(b)

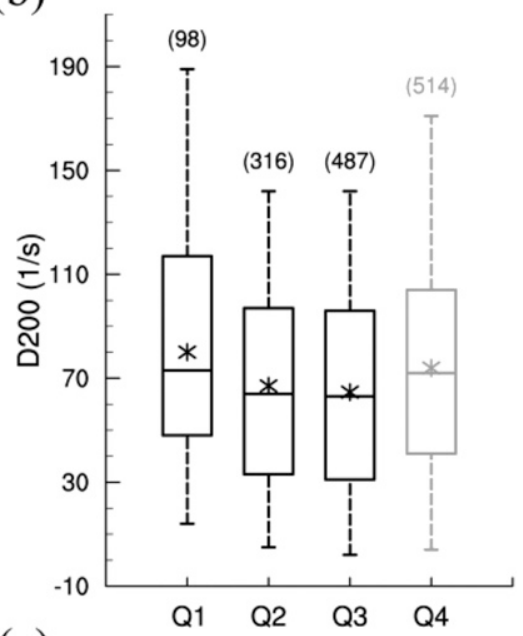

(e)

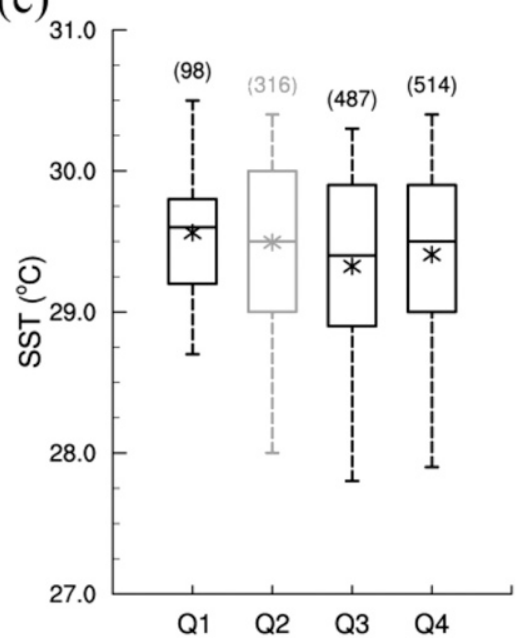

(c)

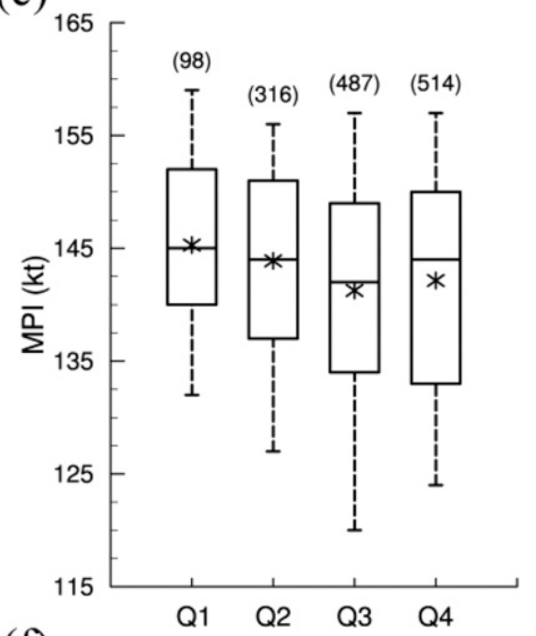

(f)

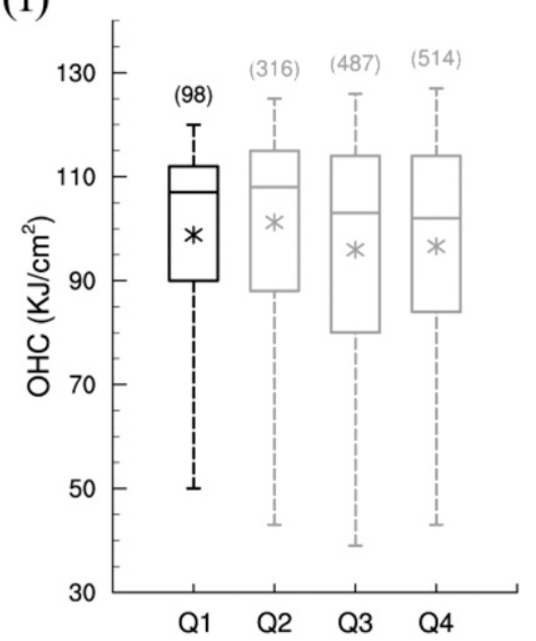

FIG. 13. Boxplots representing environmental conditions from the SHIPS data for the four quadrants depicted in Fig. 12: (a) SHRD, (b) D200, (c) MPI, (d) RHLO, (e) SST, and (f) OHC. The data ranges between the 5th and 95th percentiles of each predictor are calculated. Black boxplots in Q2-Q4 indicate that the respective values differ significantly from those in Q1 at the 95\% confidence level; gray boxplots indicate that the respective values do not differ significantly from those in Q1. Values in parentheses are the numbers of ITPs used for calculations.

When a strong TC is in a weak VWS environment, lightning distributions occur that are characterized by the greatest axial symmetry and concentration. This asymmetric pattern of lightning distribution related to TC intensity and shear strength is similar to the results obtained from satellite-derived rain rates (Chen et al. 2006; Wingo and Cecil 2010).

In this study, three lead time differences were designated, and TC lightning distributions were categorized into 15 types for composite analysis according to intensity changes in the JTWC best track data every $6 \mathrm{~h}$. However, analyses revealed negligible differences between lightning distributions at the three lead times of $-6,0$, and $+6 \mathrm{~h}$. In the future, $a+6 \mathrm{~h}$ leading time may be given preference in forecasting analysis. Among the composite analyses of five different TC intensity changes, most samples (approximately 75\%) were classified as the ST or IN type of intensity changes. The overall lightning distributions for these two types were also extremely similar, although extreme values of inner-core lightning for IN were closer to the TC center. The numbers of ITPs and flashes for WE and RI were similar; however, the spatial distribution of RI lightning was relatively concentrated in the inner core and exhibited greater symmetry. A spatial analysis of the significance of these five categories based on ST revealed that distinct differences were exhibited only for the RI type of the intensity change exhibited distinct differences and were particularly concentrated in the inner-core area near the upshear and upshearright sides, featuring several areas with significance exceeding $99 \%$. Further, quantitative calculations of the radial and innercore-azimuthal percentages yielded extremely valuable findings, which also achieved a confidence level with significance exceeding 95\% as compared to most of the other types: When RI occurs, lightning distribution is usually concentrated in the inner-core 
area and is characterized by axial symmetry. Last, the environmental conditions that contribute to concentrated and symmetric inner-core lightning features were also investigated: Storms embedded in environments with stronger upper-level divergence, warmer sea surface temperatures, and greater maximum potential intensity as well as weaker vertical wind shear were found to be potentially involved.

This finding of compact and symmetric lightning distribution resembles that of an analysis by Stevenson et al. (2018) regarding the characteristics of inner-core lightning bursts for TCs in the NA and ENP. Furthermore, this result echoes those of Rogers et al. (2013) and Wadler et al. (2018), who used composites of airborne Doppler data to examine variations in the structure and distribution of deep convection in a shearrelative framework in relation to TC intensity changes. Wadler et al. (2018) found that intensifying storms have stronger and deeper updrafts on the upshear side than steady-state storms. The physical interpretation of this result is that the stronger and deeper updrafts inside the RMW can spin up the vortex through greater angular momentum convergence and a more efficient vortex response to the diabatic heating. Thus, the observation of compact and symmetric lightning density within the RMW in this study can be useful for employing lightning data to evaluate the likelihood of RI. However, our composites did not exhibit the signal of outer rainband lightning as highlighted in the schematic of Stevenson et al. (2018). However, the occurrence of outer rainband lightning, especially over the upshear side, could indicate a decrease in shear strength causing the TC intensification. Future studies could evaluate this.

The spatial distribution of lightning in the WNP (Fig. 1) reveals that, for TCs passing through land or islands, lightning distribution and density differed substantially after contact with land. Spatial differences in lightning activity were also apparent between the South China Sea and the WNP; the South China Sea region exhibited distinctly greater lightning activity. Such topics merit further exploration. The results presented at this stage of this study primarily provide an overview of the overall lightning distribution characteristics of TCs in the WNP. We hope to discover lightning indicators that predict TC intensity changes. For instance, lightning concentration or symmetry was mentioned in the study; by quantifying and testing the relationship between such indicators and TC intensity change, we hope to find a set of lightning-related predictors, particularly for predicting RIs. Subsequent studies have begun to analyze TC cases for the NA and ENP to examine whether differences exist among the characteristics of $\mathrm{TC}$ lightning distributions in different ocean basins.

Acknowledgments. The work is supported by the National Science Council of Taiwan through Grants MOST 108-2111-M034-001, MOST 108-2811-M-034-502, and MOST 108-2119-M002-029. This manuscript was edited by Wallace Academic Editing. The TC best track data were from JTWC (http:// www.usno.navy.mil/JTWC/best-track-archive); the global lightning dataset of World Wide Lightning Location Network (http://wwlln.net/) were provided by Dr. B.-C. Chen from National Cheng Kung University (NCKU); the large-scale environmental condition data of storms were obtained the
Statistical Hurricane Intensity Prediction Scheme (http:// rammb.cira.colostate.edu/research/tropical_cyclones/ships); and the NCEP FNL operational model global tropospheric analyses were obtained from NCEP/NWS/NOAA (http://rda.ucar.edu).

\section{REFERENCES}

Abarca, S. F., K. L. Corbosiero, and D. Vollaro, 2011: The World Wide Lightning Location Network and convective activity in tropical cyclones. Mon. Wea. Rev., 139, 175-191, https:// doi.org/10.1175/2010MWR3383.1.

Bovalo, C., C. Barthe, N. Yu, and N. Bègue, 2014: Lightning activity within tropical cyclones in the southwest Indian Ocean. J. Geophys. Res. Atmos., 119, 8231-8244, https://doi.org/ 10.1002/2014JD021651.

Cangialosi, J. P., and J. L. Franklin, 2014: 2013 National Hurricane Center Forecast verification report. NOAA/National Hurricane Center, 84 pp., https:/www.nhc.noaa.gov/verification/pdfs/ Verification_2013.pdf.

Chen, S. S., J. A. Knaff, and F. D. Marks, 2006: Effects of vertical wind shear and storm motion on tropical cyclone rainfall asymmetries deduced from TRMM. Mon. Wea. Rev., 134, 3190-3208, https://doi.org/10.1175/MWR3245.1.

Chou, K.-H., C.-M. Yeh, and S.-J. Lin, 2019: The roles of vertical wind shear and topography in formation of convective asymmetries in Typhoon Nanmadol (2011). Terr. Atmos. Oceanic Sci., 30, 185-214, https://doi.org/10.3319/TAO.2018.12.16.01.

Corbosiero, K. L., and J. Molinari, 2002: The effects of vertical wind shear on the distribution of convection in tropical cyclones. Mon. Wea. Rev., 130, 2110-2123, https://doi.org/10.1175/15200493(2002)130<2110:TEOVWS > 2.0.CO;2.

- , and - 2003: The relationship between storm motion, vertical wind shear, and convective asymmetries in tropical cyclones. J. Atmos. Sci., 60, 366-376, https://doi.org/10.1175/ 1520-0469(2003)060\%3C0366:TRBSMV\%3E2.0.CO;2.

DeMaria, M., R. T. DeMaria, J. A. Knaff, and D. Molenar, 2012: Tropical cyclone lightning and rapid intensity change. Mon. Wea. Rev., 140, 1828-1842, https://doi.org/10.1175/MWR-D11-00236.1.

—, C. R. Sampson, J. A. Knaff, and K. D. Musgrave, 2014: Is tropical cyclone intensity guidance improving? Bull. Amer. Meteor. Soc., 95, 387-398, https://doi.org/10.1175/BAMS-D12-00240.1.

Ditchek, S. D., K. L. Corbosiero, R. G. Fovell, and J. Molinari, 2019: Electrically active tropical cyclone diurnal pulses in the Atlantic basin. Mon. Wea. Rev., 147, 3595-3607, https:// doi.org/10.1175/MWR-D-19-0129.1.

Dong, L., and F. Zhang, 2016: OBEST: An observation-based ensemble subsetting technique for tropical cyclone track prediction. Wea. Forecasting, 31, 57-70, https://doi.org/10.1175/ WAF-D-15-0056.1.

Fierro, A. O., and E. R. Mansell, 2017: Electrification and lightning in idealized simulations of a hurricane-like vortex subject to wind shear and sea surface temperature cooling. J. Atmos. Sci., 74, 2023-2041, https://doi.org/10.1175/JAS-D-16-0270.1.

_ and _ 2018: Relationships between electrification and storm-scale properties based on idealized simulations of an intensifying hurricane-like vortex. J. Atmos. Sci., 75, 657-674, https://doi.org/10.1175/JAS-D-17-0202.1.

- S. N. Stevenson, and R. M. Rabin, 2018: Evolution of GLMobserved total lightning in Hurricane Maria (2017) during the period of maximum intensity. Mon. Wea. Rev., 146, 1641-1666, https://doi.org/10.1175/MWR-D-18-0066.1. 
Huang, H.-C., J. Boucharel, I.-I. Lin, F.-F. Jin, C.-C. Lien, and I.-F. Pun, 2017: Air-sea fluxes for Hurricane Patricia (2015): Comparison with Supertyphoon Haiyan (2013) and under different ENSO conditions. J. Geophys. Res. Oceans, 122, 6076-6089, https:// doi.org/10.1002/2017JC012741.

Hutchins, M. L., R. H. Holzworth, J. B. Brundell, and C. J. Rodger, 2012: Relative detection efficiency of the World Wide Lightning Location Network. Radio Sci., 47, RS6005, https://doi.org/10.1029/ 2012RS005049.

Kaplan, J., and M. DeMaria, 2003: Large-scale characteristics of rapidly intensifying tropical cyclones in the North Atlantic basin. Wea. Forecasting, 18, 1093-1108, https://doi.org/10.1175/15200434(2003)018<1093:LCORIT>2.0.CO;2.

,-- , and J. A. Knaff, 2010: A revised tropical cyclone rapid intensification index for the Atlantic and eastern North Pacific basins. Wea. Forecasting, 25, 220-241, https://doi.org/10.1175/ 2009WAF2222280.1.

—_, and Coauthors, 2015: Evaluating environmental impacts on tropical cyclone rapid intensification predictability utilizing statistical models. Wea. Forecasting, 30, 1374-1396, https:// doi.org/10.1175/WAF-D-15-0032.1.

Kossin, J. P., J. A. Knaff, H. I. Berger, D. C. Herndon, T. A. Cram, C. S. Velden, R. J. Murnane, and J. D. Hawkins, 2007: Estimating hurricane wind structure in the absence of aircraft reconnaissance. Wea. Forecasting, 22, 89-101, https://doi.org/ 10.1175/WAF985.1.

Lander, M., C. Guard, and S. J. Camargo, 2014: Tropical cyclones, super typhoon Haiyan [in "State of the Climate in 2013"]. Bull. Amer. Meteor. Soc., 95 (7), S112-S114.

Lin, I.-I., I.-F. Pun, and C.-C. Lien, 2014: "Category-6" Supertyphoon Haiyan in global warming hiatus: Contribution from subsurface ocean warming. Geophys. Res. Lett., 41, 8547-8553, https:// doi.org/10.1002/2014GL061281.

Marks, F. D., and Coauthors, 1998: Landfalling tropical cyclones: Forecast problems and associated research opportunities. Bull. Amer. Meteor. Soc., 79, 305-323, https://doi.org/10.1175/ 1520-0477(1998)079<0305:LTCFPA > 2.0.CO;2.

Pan, L., X. Qie, and D. Wang, 2014: Lightning activity and its relation to the intensity of typhoons over the Northwest Pacific Ocean. Adv. Atmos. Sci., 31, 581-592, https://doi.org/10.1007/ s00376-013-3115-y.

Permyakov, M. S., T. I. Kleshcheva, E. Y. Potalova, and R. H. Holzworth, 2019: Characteristics of typhoon eyewalls according to World Wide Lightning Location Network data. Mon. Wea. Rev., 147, 4027-4043, https://doi.org/10.1175/ MWR-D-18-0235.1.

Reasor, P. D., R. F. Rogers, and S. Lorsolo, 2013: Environmental flow impacts on tropical cyclone structure diagnosed from airborne Doppler radar composites. Mon. Wea. Rev., 141, 2949-2969, https://doi.org/10.1175/MWR-D-12-00334.1.

Rodger, C. J., J. B. Brundell, R. H. Holzworth, and E. H. Lay, 2009: Growing detection efficiency of the World Wide Lightning Location Network. AIP Conf. Proc., 1118, 15-20, https:// doi.org/10.1063/1.3137706.

Rogers, R. F., P. D. Reasor, and S. Lorsolo, 2013: Airborne doppler observations of the inner-core structural differences between intensifying and steady-state tropical cyclones. Mon. Wea. Rev., 141, 2970-2991, https://doi.org/10.1175/MWR-D-12-00357.1.

, — - and J. A. Zhang, 2015: Multiscale structure and evolution of Hurricane Earl (2010) during rapid intensification.
Mon. Wea. Rev., 143, 536-562, https://doi.org/10.1175/MWRD-14-00175.1.

—, J. A. Zhang, J. Zawislak, H. Jiang, G. R. Alvey, E. J. Zipser, and S. N. Stevenson, 2016: Observations of the structure and evolution of Hurricane Edouard (2014) during intensity change. Part II: Kinematic structure and the distribution of deep convection. Mon. Wea. Rev., 144, 3355-3376, https:// doi.org/10.1175/MWR-D-16-0017.1.

Stevenson, S. N., K. L. Corbosiero, and J. Molinari, 2014: The convective evolution and rapid intensification of Hurricane Earl (2010). Mon. Wea. Rev., 142, 4364-4380, https://doi.org/ 10.1175/MWR-D-14-00078.1.

,-- , and S. F. Abarca, 2016: Lightning in eastern North Pacific tropical cyclones: A comparison to the North Atlantic. Mon. Wea. Rev., 144, 225-239, https://doi.org/10.1175/MWRD-15-0276.1.

,-- M. DeMaria, and J. L. Vigh, 2018: A 10-year survey of tropical cyclone inner-core lightning bursts and their relationship to intensity change. Wea. Forecasting, 33, 23-36, https://doi.org/10.1175/WAF-D-17-0096.1.

Thomas, J. N., N. Solorzano, S. A. Cummer, and R. H. Holzworth, 2010: Polarity and energetics of inner core lightning in three intense North Atlantic hurricanes. J. Geophys. Res., 115, A00E15, https://doi.org/10.1029/2009JA014777.

Velden, C., and Coauthors, 2006: The Dvorak tropical cyclone intensity estimation technique: A satellite-based method that has endured for over 30 years. Bull. Amer. Meteor. Soc., 87, 1195-1210, https://doi.org/10.1175/BAMS-87-9-1195.

Wadler, J. B., R. F. Rogers, and P. D. Reasor, 2018: The relationship between spatial variations in the structure of convective bursts and tropical cyclone intensification as determined by airborne Doppler radar. Mon. Wea. Rev., 146, 761-780, https://doi.org/ 10.1175/MWR-D-17-0213.1.

Wang, F., X. S. Qie, D. F. Wang, and A. Srivastava, 2018: Lightning activity in tropical cyclones and its relationship to dynamic and thermodynamic parameters over the northwest Pacific. Atmos. Res., 213, 86-96, https://doi.org/10.1016/j.atmosres.2018.05.027.

Wingo, M. T., and D. J. Cecil, 2010: Effects of vertical wind shear on tropical cyclone precipitation. Mon. Wea. Rev., 138, 645662, https://doi.org/10.1175/2009MWR2921.1.

$\mathrm{Xu}$, W., S. A. Rutledge, and W. Zhang, 2017: Relationships between total lightning, deep convection, and tropical cyclone intensity change. J. Geophys. Res. Atmos., 122, 7047-7063, https://doi.org/10.1002/2017JD027072.

Zhang, W., Y. Zhang, D. Zheng, and X. Zhou, 2012: Lightning distribution and eyewall outbreaks in tropical cyclones during landfall. Mon. Wea. Rev., 140, 3573-3586, https://doi.org/ 10.1175/MWR-D-11-00347.1.

_,,$- \ldots$, F. Wang, and L. Xu, 2015: Relationship between lightning activity and tropical cyclone intensity over the northwest Pacific. J. Geophys. Res. Atmos., 120, 4072-4089, https://doi.org/10.1002/2014JD022334.

$\ldots,-, \ldots$, L. Xu, and W. Lyu, 2018: Lightning climatology over the Northwest Pacific region: An 11-year study using data from the World Wide Lightning Location Network. Atmos. Res., 210, 41-57, https://doi.org/10.1016/j.atmosres.2018.04.013.

—_, S. A. Rutledge, W. Xu, and Y. Zhang, 2019: Inner-core lightning outbreaks and convective evolution in Super Typhoon Haiyan (2013). Atmos. Res., 219, 123-139, https:// doi.org/10.1016/j.atmosres.2018.12.028. 